\title{
A Novel Comprehensive Quantitative Method for Various Geological Disaster Evaluations in Underground Engineering: Multidimensional Finite Interval Cloud Model (MFICM)
}

\author{
Tianhua Wu \\ University of Science and Technology Beijing \\ Yongtao Gao \\ University of Science and Technology Beijing \\ Yu Zhou ( $\nabla$ westboy85@ustb.edu.cn ) \\ University of Science and Technology Beijing https://orcid.org/0000-0003-4247-299X \\ Hao Sun \\ University of Science and Technology Beijing
}

\section{Research Article}

Keywords: risk evaluation, cloud model, analytic hierarchy process (AHP), principal component analysis (PCA), geological disasters, engineering applications

Posted Date: May 7th, 2021

DOI: https://doi.org/10.21203/rs.3.rs-482446/v1

License: (c) (i) This work is licensed under a Creative Commons Attribution 4.0 International License.

Read Full License 
A novel comprehensive quantitative method for various geological disaster evaluations in underground engineering: Multidimensional finite interval cloud model (MFICM)

Tianhua $\mathrm{Wu}^{\mathrm{a}, \mathrm{b}}$, Yongtao Gao ${ }^{\mathrm{a}, \mathrm{b}}$, Yu Zhou ${ }^{\mathrm{a}, \mathrm{b}^{*}}$, Hao Sun ${ }^{\mathrm{a}, \mathrm{b}}$

${ }^{\text {a }}$ Key Laboratory of Ministry for Efficient Mining and Safety of Metal Mines, University of Science and Technology Beijing, Beijing 100083, China

${ }^{\mathrm{b}}$ School of Civil and Resource Engineering, University of Science and Technology Beijing, Beijing 100083, China

*Corresponding author: Yu Zhou, Department of Resource Engineering University of Science and Technology Beijing 30 Xue Yuan Lu (College Road), Beijing 100083, China

Tel: +8610 62333623, Cell: +8613581610996 E-mail: westboy85@ustb.edu.cn.

\begin{abstract}
The risk prediction of geological disasters exhibits extreme uncertainty and complexity due to the random distribution of evaluation indexes within a finite interval. To improve the accuracy of disaster prediction results, a new evaluation method is in this study suggested to perform a risk evaluation of geological disasters based on multidimensional finite interval cloud model (MFICM) and combination weighting. The MFICM with a transformation between qualitative concept and quantitative data depicts uncertainties and actual distribution features of indexes in the finite
\end{abstract}


interval. Analytic hierarchy process (AHP) and principal component analysis (PCA) are adopted to determine the subjective and objective weights of evaluation indexes, respectively, and the combination weight is calculated by a linear method to reduce the influence of subjective factors. The numerical characteristic parameters of each indexes belonging to various risk levels are first calculated based on established evaluation index system. Subsequently, a multi-dimensional finite interval cloud is generated from a forward cloud generator using MATLAB software. Finally, the comprehensive certainty degrees relative to different levels for each sample are determined combined with combination weight, which achieves a mapping of uncertainty between semantic variables and index values. The proposed method is applied to engineering cases regarding three geological disasters, i.e., water inrush, rock burst and collapse. The obtained results with accuracy and results comparison with reference methods show that the MFICM is verified to be practical and universal for the risk evaluation of geological disasters, which improves and enriches the theoretical framework of geotechnical engineering disaster risk evaluation.

Keywords: risk evaluation; cloud model; analytic hierarchy process (AHP); principal component analysis (PCA); geological disasters; engineering applications

\section{Introduction}

In recent years, with the vigorous development of national infrastructure, underground engineering construction in China has rapidly developed at a large scale. Geological disasters, such as water inrush, large deformation, gas outburst, rock burst and collapse, are encountered in the construction of underground engineering due to the existence of fault fracture zones, joints, karst caves and high geostress. Hence, it is critical to perform risk assessments and safety 
management to ensure the safe and efficient construction of underground engineering.

Numerous geological evaluation models and mathematical theory methods, proposed by many research scholars, have been applied to conduct the risk assessment of geological disasters such as water inrush, rock burst and collapse (Brown 2012; Beard 2010). For water inrush risk evaluation, Wang et al. (2019a, 2019b, 2019c) carried out a risk assessment of water inrush from karst tunnels and coal mine floors using a one-dimensional normal cloud model and a fuzzy interval-analytic hierarchy process (AHP) method which was verified by comparing it with on-site construction results. Similarly, with regard to rock burst risk evaluation, a traditional multidimensional normal cloud considering the comprehensive effect of multiple evaluation indicators was suggested by Guo et al. (2018). Using a fuzzy comprehensive evaluation model, Cai et al. (2018) successfully predicted the rock burst level in deeply buried coal mines based on subsurface microseismic data. Liang et al. (2019) demonstrated the feasibility of an extended multiattributive border approximation area comparison (MABAC) method for rock burst evaluation. Wang et al. (2019d) established an interval fuzzy comprehensive model that had been favorably applied in the evaluation of the rock burst risk of the Jiangbian hydropower station. Study related to risk evaluation of tunnel collapse include a grey correlation-entropy method which was verified to be proposed by Gao et al. (2017). Sun et al. (2018) presented a multistate fuzzy Bayesian network that could ensure the precision and scientific rigor of the predicted results and consequently the diagnosis of a tunnel accident. With an analysis model combining case-based reasoning, advanced geological prediction, and rough set theory, Zhang et al. (2016) carried out a risk evaluation of mountain tunnel collapse, and the evaluation result based on this model was feasible and reliable. 
The above studies have greatly contributed to the research system of risk evaluation of geological disasters. However, the above-mentioned evaluation methodologies regrading different geological disaster do not have a systematic consideration on geotechnical uncertainties of randomness and fuzziness of factor indexes in a uniform manner (Wang et al. 2007; Li et al. 2009), which may cause that there is some discrepancy between prediction results and actual condition. Additionally, although the existing clouds such as one-dimensional and multi-dimensional normal cloud model (Luo et al. 2020; Yan et al. 2017) have considered above two uncertainties, they may fail to embody the dependence and interaction responses of multiple indexes in the generation of cloud drop and depict actual distribution of uncertainty indexes in the finite interval, and it may also easily lead to distortion of evaluation results.

This study is aimed at evaluating the risk levels of three geological disasters regarding water inrush, rock burst and tunnel collapse based on cloud model theory. A novel cloud method named multidimensional finite interval cloud model (MFICM), considering uncertainties and actual distribution characteristics of indexes in the finite interval, implementing a conversion between qualitative concept and quantitative factors, is proposed in this work. The practicability and universality of the proposed model are analyzed by three types of engineering case studies.

The organization framework of this paper is as follows: Section 2 describes the basic process of establishing the combination weight of the evaluation index. The geological disaster risk evaluations based on MFICM, including evaluation framework, general concept and algorithm flow of the proposed model, determination of comprehensive certainty degree, is discussed in Section 3. The MFICM, in Section 4, is applied to the risk prediction regarding three geological disasters for different engineering cases. Section 5 discusses briefly the shortcomings of this paper 
and the current limitations and future prospects of the MFICM. Finally, some main conclusions are given in Section 6.

\section{Establishment of combined weight model}

Accurately determining the weights of indexes plays an important role in obtaining a reasonable disaster risk level result. In the present work, the AHP method is used to determine the subjective weight and the PCA method is adopted to calculate the objective weight. Subsequently, a linear combination method is used to obtain the subjective and objective combination weights. A general process for the establishment of combination weights is illustrated in Fig. 1.

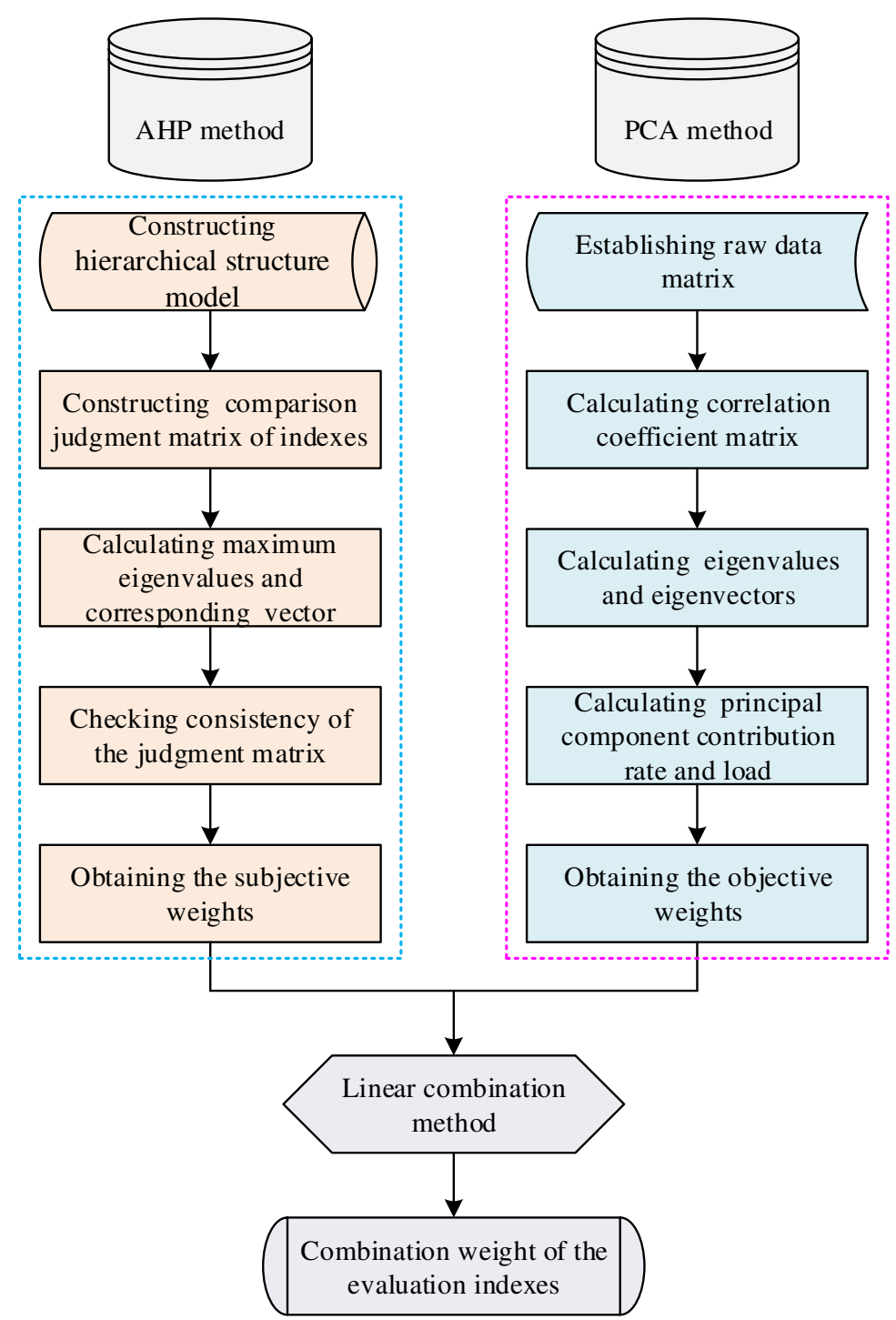

Fig. 1 A general process for the establishment of combination weights. 


\subsection{Determination of subjective weight}

The analytic hierarchy process (AHP), first proposed by Saaty $(1990,2008)$, is a complex multiobjective decision analysis method. The AHP method enables us to systematize, hierarchize and quantify the existing intricate problems, thereby determining the importance of the factors that affect the target object. In the present study, the AHP method is adopted to obtain the subjective weights of the relevant evaluation factors ( $\mathrm{Li}$ et al. 2017; Tudes and Yigiter 2010). The general steps of the AHP are as follows:

Step 1: a hierarchical structure model of risk indicators is established for geological disasters.

Step 2: the 1 9 scale method constructed by Saaty (2003) is used to determine the judgment matrix $P$ of the related factors based on the scoring method by expert reviews.

Step 3: with judgment matrix $P$, obtain the maximum eigenvalues and the corresponding weight vector (Eqs. (1) and (2)).

Step 4: the consistency of the judgment matrix $P$ is checked to ensure the accuracy of the results (Eq. (3)). The main calculation formulas are given below.

$$
\begin{aligned}
& w_{i}=\left(\prod_{j=1}^{n} P_{i j}\right)^{1 / n} / \sum_{i=1}^{n}\left(\prod_{j=1}^{n} P_{i j}\right)^{1 / n} \\
& \lambda_{\max }=\left(\sum_{i=1}^{n}\left((P w)_{i} / w_{i}\right)\right) / n \\
& C R=\left\{\left(\lambda_{\max }-n\right) /(n-1)\right\} / R I
\end{aligned}
$$

where $\lambda_{\max }$ denotes a maximum eigenvalue; $n$ is the order of the judgment matrix; $w_{i}$ is the weight value of the $i$ th factor index $(i=1,2, \ldots, n) ; w=\left(w_{1}, w_{2}, \ldots, w_{n}\right)$ is the weight vector of the matrices $P ; R I$ is the average random consistency index; and $C R$ is a consistency index (required to meet $C R<0.1$ ). 


\subsection{Determination of objective weight}

The principal component analysis (PCA) is an objective statistical analysis method that acquires the weight of factor indexes from the correlations of the sample information of the evaluation object (Shafiullah and Al-Ruwaih 2020). The PCA method, based on the idea of dimensionality reduction, can transform multiple variables that are correlated normally into several newly comprehensive variables that are uncorrelated or orthogonal (Li and Yan 2018; Wold et al. 1987). Since these variables are usually multidimensional and correlated in the risk assessment system of geological disasters, the PCA method was used in this study to determine the objective weights of the evaluation index based on certain sample information data. The general steps of PCA to calculate the objective weights are described as follows (Moore 1981; Xue et al. 2019):

Step 1: assuming there are $t$ samples of certain geological disasters and $n$ evaluation indexes for each sample, a data matrix $A$ with $t \times n$ dimensions is constructed (Eq. (4)).

Step 2: the correlation coefficient matrix $R$ is calculated (Eq. (5)).

Step 3: the eigenvalues and eigenvectors are calculated. Eigenvalues are ranked in order of $\lambda_{1} \geq \lambda_{2} \geq \ldots \geq \lambda_{n}>0$, and the unit eigenvector $e_{i}(i=1,2, \ldots, n)$ (i.e., $\sum_{j=1}^{n} e_{i j}^{2}=1$, where $e_{i j}$ denotes the $j_{\text {th }}$ component of $e_{i j}$ ) corresponding to the eigenvalues can be obtained.

Step 4: the principal component contribution rate $f(i)$ and principal component load $F(b)$ are calculated using Eqs. (6) and (7).

Step 5: Eq. (8) is used to obtain the objective weight $w_{j}$. 
$A=\left[\begin{array}{cccc}a_{11} & a_{12} & \mathrm{~L} & a_{1 n} \\ a_{21} & a_{22} & \mathrm{~L} & a_{2 n} \\ \mathrm{M} & \mathrm{M} & & \mathrm{M} \\ a_{t 1} & a_{t 2} & \mathrm{~L} & a_{t n}\end{array}\right]$

$R=\left[\begin{array}{cccc}r_{11} & r_{12} & \mathrm{~L} & r_{1 n} \\ r_{21} & r_{22} & \mathrm{~L} & r_{2 n} \\ \mathrm{M} & \mathrm{M} & & \mathrm{M} \\ r_{m 1} & r_{m 2} & \mathrm{~L} & r_{m n}\end{array}\right]$

$f(i)=\lambda_{i} / \sum_{t=1}^{n} \lambda_{t} \quad(i=1,2, \ldots, n)$

$F(b)=\sum_{i}^{b} f(i) \quad(i=1,2, \ldots, n)$

$w_{j}=\frac{\left|\sum_{i}^{b} f(i) \mathscr{E}_{i j}\right|}{\sum_{j}^{n}\left(\left|\sum_{i}^{b} f(i) \mathscr{E}_{i j}\right| / F(b)\right)}$

\subsection{Combination weight}

To reflect the importance of each factor index as accurately as possible in the multi-indicator evaluation system, a combination weight method that enables us to consider both the significance of factor indexes and the strength of the objective data competition significance is presented. Therefore, a commonly used linear weighted combination method is adopted in this study to calculate the final weight of the factor indexes, as shown in Eq. (9). According to the study of Li et al. (2013a), both weight coefficients $\varphi_{1}=0.5$ and $\varphi_{2}=0.5$ in the present work are determined.

$$
\left\{\begin{array}{l}
W=\varphi_{1} w_{i}+\varphi_{2} w_{j} \\
\varphi_{1}+\varphi_{2}=1
\end{array}\right.
$$

\section{Establishment of geological disaster risk evaluations system}

\subsection{Evaluation framework based on MFICM model}


Fig. 2 illustrates a basic framework for risk evaluation of various geological disasters encountered in the construction of underground engineering with the MFICM. For the convenience and clarity of description, the water inrush hazard is taken as an example to describe and explain the process of risk assessment using the MFICM. The description is given as follows:

Step 1: According to previous works on the mechanism and cause of water inrush, an appropriate and reasonable multi-indicator evaluation system for the probability of water inrush disaster is constructed with the selected evaluation indicators and level criteria.

Step 2: Numerical characteristic parameters of MFICM with $k$ indicators and $t$ levels are assigned based on the level criteria of the factor indexes of water inrush combined with cloud model theory.

Step 3: A linear combination of the objective weight $w_{i}$ obtained by AHP and subjective weight $w_{j}$ obtained by PCA are used to determine the combination weight $W$ of the factor indexes.

Step 4: A $k$-dimensional finite interval cloud with $t$ levels is generated in light of the above numerical characteristic parameters, and combining the weight $W$ and the measured values of the factor indexes of water inrush, a comprehensive certainty degree belonging to different risk levels of the water inrush for a sample is obtained.

Step 5: The final risk level of water inrush for a sample is specified using the principle of maximum membership. 


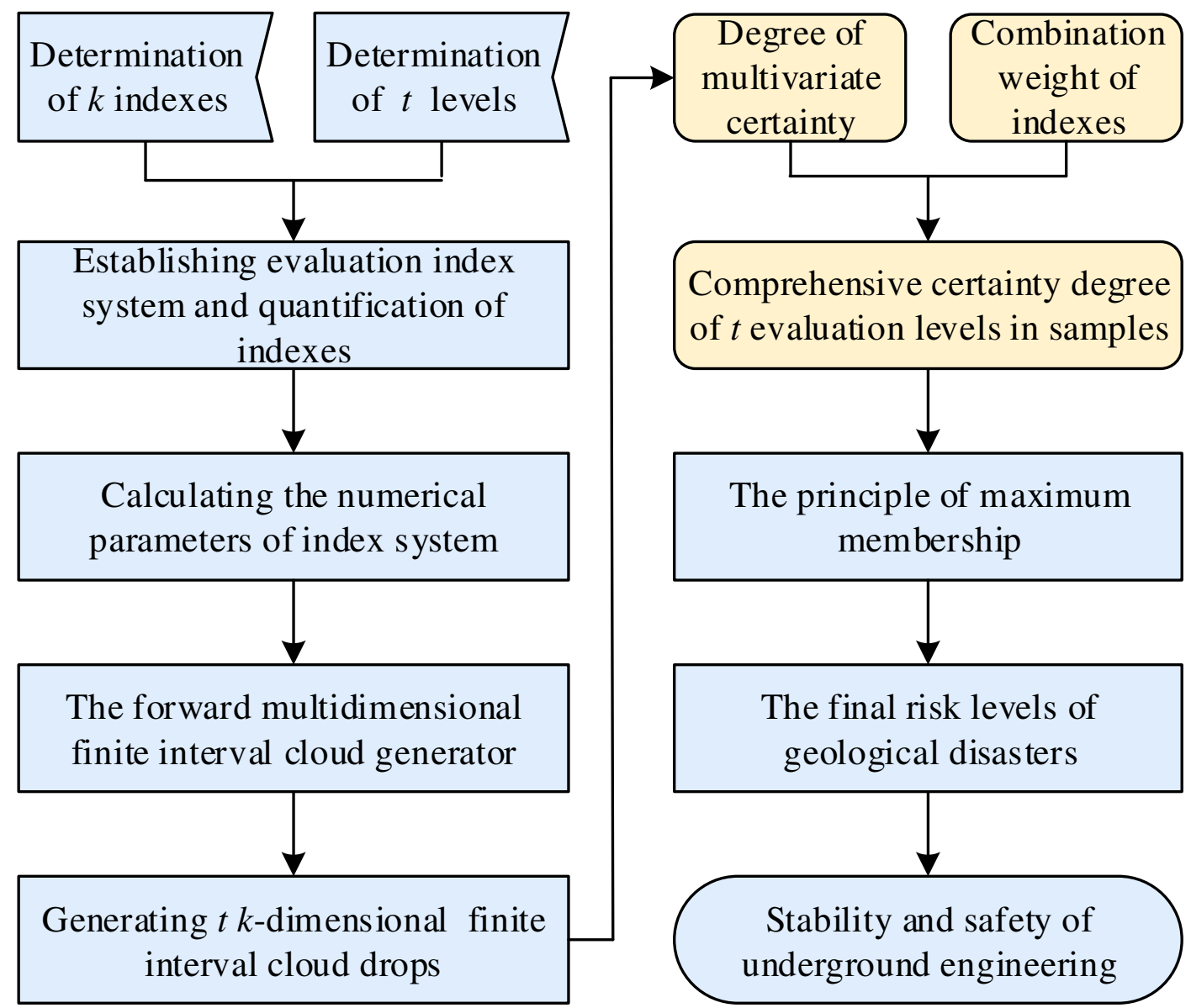

Fig. 2 A framework of geological disaster risk assessment by the MFICM.

\subsection{Concept of the MFICM model}

Cloud, has the capability to not only provide an explanation from classic random theory and fuzzy set theory but also reflect the relevance of randomness and fuzziness. It provides an uncertainty conversion model between a qualitative concept expressed by linguistic values and its quantitative expression. The definition of a cloud is given as ( $\mathrm{Li}$ and $\mathrm{Du} 2014$ ): Assume a qualitative concept $M$ defined over a finite interval universe of discourse $N$ represented by exact values. If quantitative number $x \in N$ and $x$ is a random realization of the qualitative concept $M$, the certainty degree $\mu(x) \in[0,1]$ of $x \in N$ is a random number with a stable tendency. The parameter $\mu(x) \in[0,1]$ is obtained as:

$\mu: N \rightarrow[0,1], \quad \forall x \in N, x \rightarrow \mu(x)$ 
where the distribution of $x$ over a universe of discourse $N$ is referred to as a cloud, and $x$ represents cloud droplets.

Three main numerical characteristic parameters, i.e., expectation $E x$, entropy $E n$, and hyper-entropy $H e$, are used in the cloud model to fully characterize the qualitative concept $M$. Expectation $(E x)$ is the expected value in the distribution of a universe of discourse. Entropy (En) denotes an uncertainty measure for the qualitative concept, which implies a possible distribution range of cloud droplets. Hyper-entropy $(\mathrm{He})$ reveals the degree of dispersion of cloud droplets, reflecting uncertainty and randomness, as shown in Fig. 3.

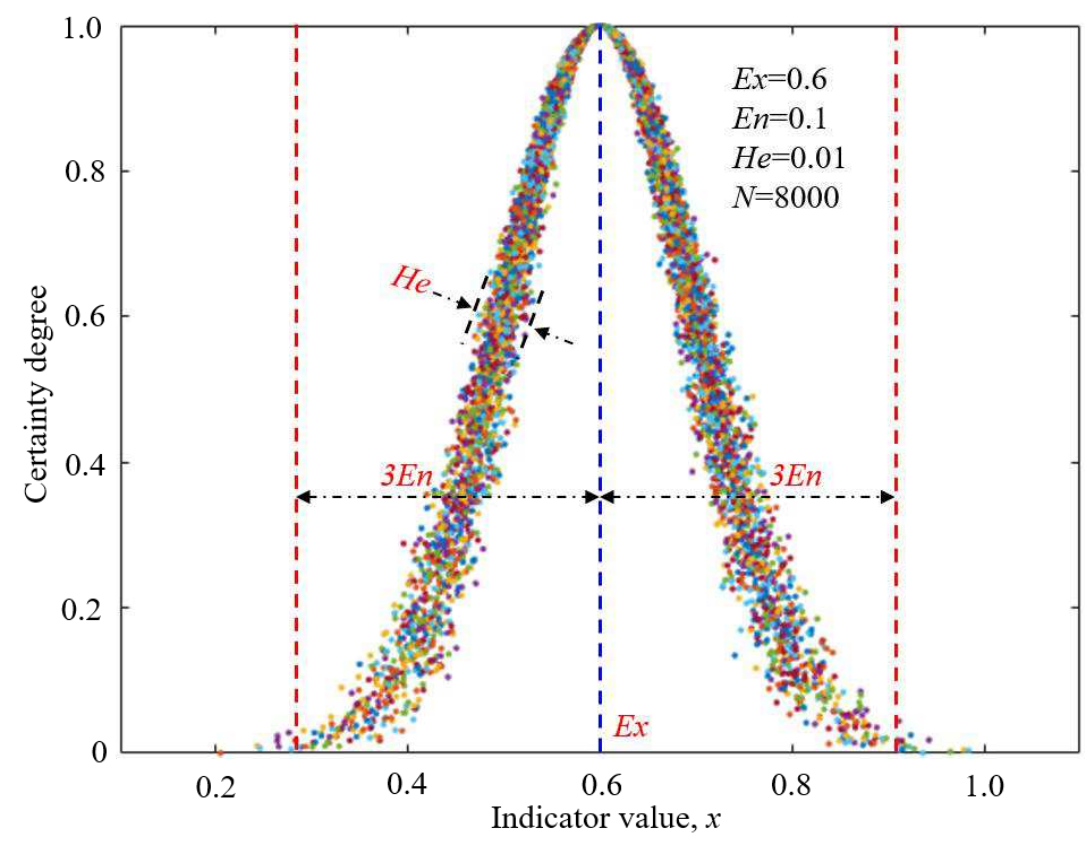

Fig. 3 An illustration of the numerical characteristics of the normal cloud model.

Since there are no exact definite criteria for the numerical characteristic parameters ( $E x, E n$ and $\mathrm{He}$ ) of the multidimensional cloud model, previous studies (Wang et al. 2016a; Guo et al. 2018) can be referenced to obtain the characteristic parameters of the MFICM. The specific calculation formulas are as follows:

$E x^{i}=\left(B_{\max }^{i}+B_{\min }^{i}\right) / 2$ 


$$
\begin{aligned}
& E n^{i}=\max \left(E x^{1}, E x^{2}, \ldots, E x^{i}\right) / 3 \\
& H e^{i}=\varphi E n^{i}
\end{aligned}
$$

where $B_{\max }^{i}$ and $B_{\min }^{i}$ denote the minimum and maximum values of level interval $i$, respectively, and $\varphi$, which aims to manage the degree of aggregation about cloud droplets within the level cloud, is an empirical coefficient constant and can be adjusted according to the fuzzy threshold of the index variable.

Given a qualitative concept $M\left(E_{x}, E_{n}, H_{e}\right)$ defined over a $k$-dimensional universe of discourse $N\left\{x_{1}, x_{2}, \ldots, x_{k}\right\}$ represented by exact values, if there is a quantitative number $x\left(x_{1}, x_{2}, \ldots, x_{k}\right) \quad(x \in N)$ that is a random realization of qualitative concept $M$ and follows a normal distribution $x\left(x_{1}, x_{2}, \ldots, x_{k}\right): N\left(E x\left(E x_{1}, E x_{2}, \ldots, E x_{k}\right), E n^{\prime}\left(E n_{1}^{\prime}, E n_{2}^{\prime}, \ldots, E n_{k}^{\prime}\right)^{2}\right)$, where $\quad n^{\prime} \quad$ satisfies $\quad$ a $\quad$ normal distribution $E n^{\prime}\left(E n_{1}^{\prime}, E n_{2}^{\prime}, \ldots, E n_{k}^{\prime}\right): N\left(E n\left(E n_{1}, E n_{2}, \ldots, E n_{k}\right), H e\left(H e_{1}, H e_{2}, \ldots, H e_{k}\right)^{2}\right)$, accordingly, the overall quantitative certainty degree of $\boldsymbol{x}$ belonging to concept $M$ is characterized as ( $\mathrm{Li}$ and Du 2014; Wang et al. 2016a):

$\mu\left(x\left(x_{1}, x_{2}, \ldots, x_{k}\right)\right)=\exp \left(-\sum_{i=1}^{k} \frac{\left(x_{i}-E x_{i}\right)^{2}}{2\left(E n_{i}^{\prime}\right)^{2}}\right) \quad(i=1,2, \ldots, k)$

where the distribution of $x\left(x_{1}, x_{2}, \ldots, x_{k}\right)$ over a universe of discourse $N$ is referred to as a $k$-dimensional normal cloud.

However, in the evaluation process of disaster risk levels of underground engineering, the division of the risk levels will inevitably have the unilateral constraint intervals (i.e., $\left[B_{\min }^{i},+\infty\right]$ and $\left[0, B_{\max }^{i}\right]$ ). In this situation, the evaluation index does not completely obey a normal distribution, and some differences are observed in the shape of the cloud model. That is, when the 
evaluation index $\boldsymbol{x}$ is in the interval between the cloud mean of the two levels, $\boldsymbol{x}$ obeys an absolute normal distribution in the finite interval. When the evaluation index $\boldsymbol{x}$ is far from the expectation of level interval, $\boldsymbol{x}$ obeys uniform distribution with certainty degree of 1 . At the same time, half-rising trapezoidal clouds or half-falling trapezoidal clouds can be commonly adapted to describe relevant information. Fig. 4 shows a schematic of the one-dimensional and two-dimensional finite interval cloud model. It can be seen from Fig. 4 that the risk levels I and V belong to unilateral constraint intervals $\left(\left[B_{\min }^{i},+\infty\right]\right.$ and $\left.\left[0, B_{\max }^{i}\right]\right)$, and while the rest levels (II, III, IV) are bilateral constraint intervals $\left(\left[B_{\min }^{i}, B_{\max }^{i}\right]\right)$ that follows the normal distribution.

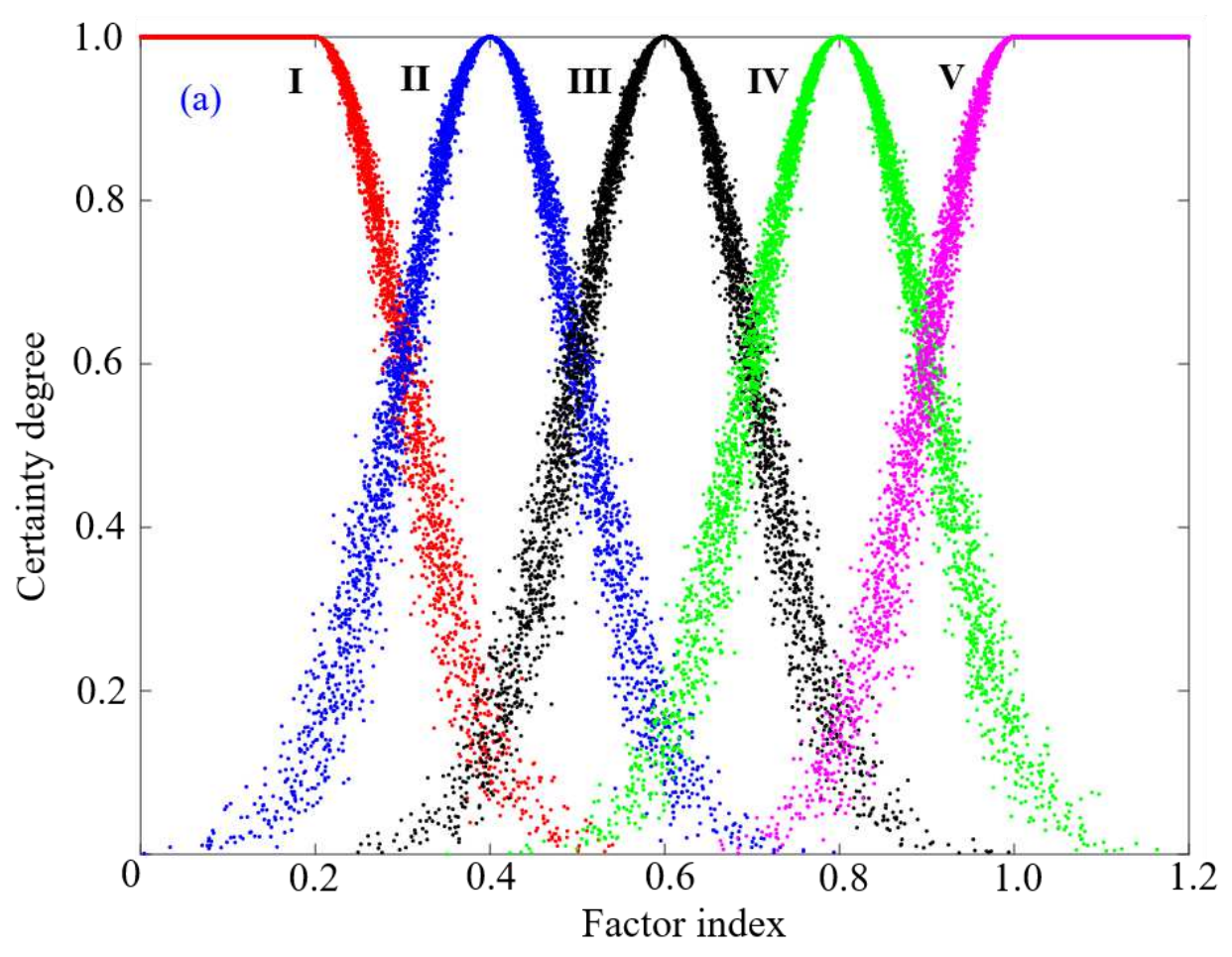




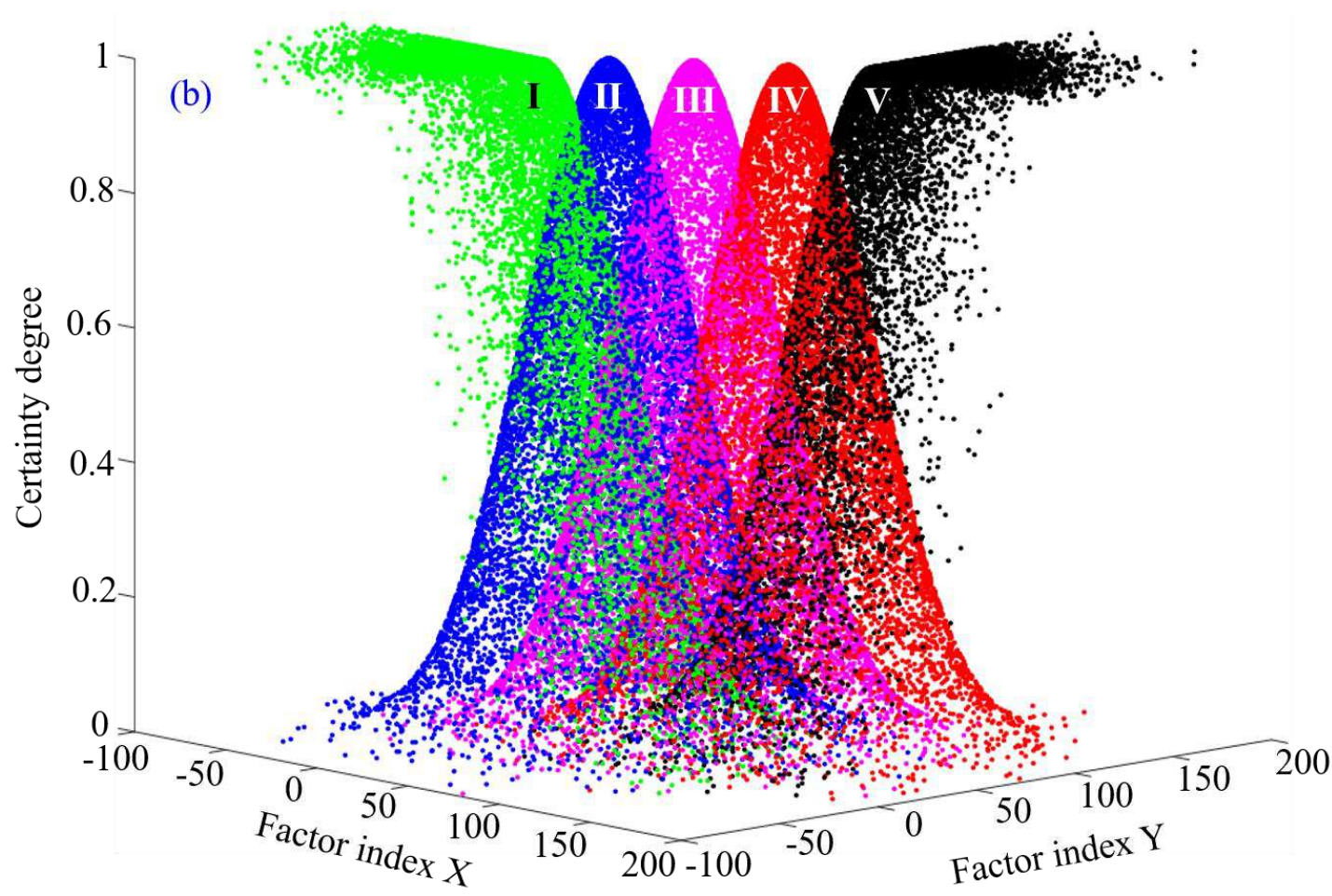

Fig. 4 A schematic of the one-dimensional (a) and two-dimensional (b) finite interval cloud model.

\subsection{Forward cloud generator and algorithm flow of the MFICM}

Cloud generators (also referred to as cloud generation algorithms), including forward cloud generators and backward cloud generators, are the key to the application of cloud models ( $\mathrm{Li}$ and Liu 2010). In the cloud model theory described above, the forward cloud generator is used in the present work to generate the multidimensional finite interval cloud model so as to achieve transformation of qualitative concepts into quantitative concepts. The specific algorithm flows are as follows:

Input: Numerical characteristic parameters $\left(E x_{1}, E x_{2}, \ldots, E x_{k}, E n_{1}, E n_{2}, \ldots, E n_{k}, H e_{1}, H e_{2}, \ldots ., H e_{k}\right)$ are used to generate the cloud droplet number $K$.

Output: Cloud droplets $\operatorname{drop}\left(x_{1 j}, x_{2 j}, \ldots, x_{k j}, \mu_{j}\right) \quad(j=1,2, \ldots, K)$. 


\section{Algorithm flow:}

Step 1: Calculate the numerical characteristic parameters of the MFICM $\left(E x_{1}, E x_{2}, \ldots, E x_{k}, E n_{1}, E n_{2}, \ldots, E n_{k}, H e_{1}, H e_{2}, \ldots ., H e_{k}\right)$.

Step 2: Generate $k$-dimensional normal random numbers $E n^{\prime}\left(E n_{1}^{\prime}, E n_{2}^{\prime}, \ldots, E n_{k}^{\prime}\right)$ with expectation $E n\left(E n_{1}, E n_{2}, \ldots, E n_{k}\right)$ and variance $H e\left(H e_{1}, H e_{2}, \ldots, H e_{k}\right)^{2}$.

Step 3: Generate $k$-dimensional normal random numbers $x\left(x_{1}, x_{2}, \ldots, x_{k}\right)$ with expectation $E x\left(E x_{1}, E x_{2}, \ldots, E x_{k}\right)$ and variance $E n^{\prime}\left(E n_{1}^{\prime}, E n_{2}^{\prime}, \ldots, E n_{k}^{\prime}\right)^{2}$.

Step 4: Calculate $\mu_{j}\left(x\left(x_{1}, x_{2}, \ldots, x_{k}\right)\right)=\exp \left(-\sum_{i=1}^{k} \frac{\left(x_{i j}-E x_{i}\right)^{2}}{2\left(E n_{i j}^{\prime}\right)^{2}}\right) \quad(i=1,2, \ldots, k)$, thus, a particular cloud droplet of the MFICM is defined as $\operatorname{drop}\left(x\left(x_{1}, x_{2}, \ldots, x_{k}\right), \mu_{j}\left(x\left(x_{1}, x_{2}, \ldots, x_{k}\right)\right)\right)$. It is worth noting that when the level interval of the evaluation index is a unilateral constraint, and the evaluation index is far from the expectation of level interval, the certainty degree $\mu_{j}\left(x\left(x_{1}, x_{2}, \ldots, x_{k}\right)\right)=1 \quad(i=1,2, \ldots, k)$.

Step 5: Repeat steps 2 4 until $K$ cloud droplets are generated.

\subsection{Determination of comprehensive certainty degree}

According to Eq. (14), the certainty degrees of the evaluation indexes whose measured values pertain to a certain level are obtained. Combining with the combination weights of indexes $W_{i}$, a comprehensive certainty degree $\mu_{c}$ of the risk level for the evaluation samples is obtained based on the following formula:

$\mu_{c}\left(x\left(x_{1}, x_{2}, \ldots, x_{k}\right)\right)=\exp \left(-\sum_{i=1}^{k} \frac{W_{i}\left(x_{i}-E x_{i c}\right)^{2}}{2\left(E n_{i}^{\prime}\right)^{2}}\right) \quad(i=1,2, \ldots, k ; c=1,2, \ldots, l)$

where $\mu_{c}\left(x\left(x_{1}, x_{2}, \ldots, x_{k}\right)\right) \quad(c=1,2, \cdots l)$ denotes the comprehensive certainty degree that an 
evaluation sample belongs to the $c$-th level of risk, and $l$ in this work is equal to 4 .

Based on the comprehensive certainty degree, the final risk level $Q$ is obtained judging by the principle of maximum membership:

$$
Q=\max \left\{\mu_{1}, \mu_{2}, \cdots \mu_{c}\right\}
$$

\section{Engineering applications}

For the sake of verifying and validating on the universality and practicality of the proposed model, MFICM is adopted to implement a risk prediction relative to three geological disasters (water inrush, rock burst and collapse) for different engineering cases. For each engineering case, three major aspects, i.e., i) evaluation system and case data; ii) weight of evaluation indexes; and iii) validation and application of MFICM, are investigated in detail in this work.

\subsection{Case 1: Application of MFICM to water inrush risk assessment in Jigongling Tunnel}

\subsubsection{Evaluation system and case data}

Water inrush has become one of the most severe and common geological disasters encountered during the construction of the karst tunnels. In this work, taking the Jigongling Tunnel as the background, the MFICM method is adopted to carry out the prediction of water inrush risk. A detailed description of the Jigongling Tunnel can be found in the study of Li et al. (2013a). Seven factor indexes, namely, formation lithology $\left(U_{1}\right)$, unfavorable geological conditions $\left(U_{2}\right)$, groundwater level $\left(U_{3}\right)$, landform and physiognomy $\left(U_{4}\right)$, strata inclination $\left(U_{5}\right)$, contact zones of dissolvable and insoluble rock $\left(U_{6}\right)$, and layer and interlayer fissures $\left(U_{7}\right)$, are chosen as evaluation indexes of water inrush. The risk of water inrush is divided into four levels: high risk (I), moderate risk (II), low risk (III), and very low risk (IV). Table 1 and Table 2 present 
the level criteria and field measured values of the evaluation indexes of water inrush in Jigongling Tunnel, respectively (Li et al. 2013a, 2013b; Zhou et al. 2015).

\subsubsection{Weight of evaluation indexes}

It is worth noting that due to the limited samples (Table 2) given in the study of $\mathrm{Li}$ et al. (2013a), a determination of the objective weight of the evaluation indexes associated with water inrush fails to be achieved using the PCA method proposed in the present study. Consequently, to obtain a better comparison, the values of the subjective weight $\left(w_{i}\right)$, objective weight $\left(w_{j}\right)$ and comprehensive weight $(W)$ of the evaluation indexes, in this case, are identical to the values presented in the literature mentioned above, as shown in Table 1.

Table 1 Factor indexes and level criteria of water inrush in tunnels

\begin{tabular}{|c|c|c|c|c|c|c|c|}
\hline \multirow{2}{*}{$\begin{array}{l}\text { Factor indexes associated with } \\
\text { water inrush }\end{array}$} & \multicolumn{4}{|c|}{ The risk levels of water inrush } & \multirow{2}{*}{$w_{i}$} & \multirow{2}{*}{$w_{j}$} & \multirow{2}{*}{$W$} \\
\hline & I(high) & II(moderate) & III(low) & IV(very low) & & & \\
\hline Formation lithology $\left(U_{1}\right)$ & $85-100$ & $70-85$ & $60-70$ & $50-60$ & 0.178 & 0.155 & 0.167 \\
\hline $\begin{array}{l}\text { Unfavorable geological conditions } \\
\left(U_{2}\right)\end{array}$ & $85-100$ & $70-85$ & $60-70$ & $50-60$ & 0.350 & 0.349 & 0.350 \\
\hline Groundwater level, m $\left(U_{3}\right)$ & $60-90$ & $30-60$ & $10-30$ & $0-10$ & 0.178 & 0.173 & 0.176 \\
\hline $\begin{array}{l}\text { Landform and physiognomy }\left(U_{4}\right) \\
\text { (proportion of negative landform } \\
\text { area, \%) }\end{array}$ & $60-80$ & $40-60$ & $20-40$ & $0-20$ & 0.098 & 0.095 & 0.097 \\
\hline Modified strata inclination, ${ }^{\circ}\left(U_{5}\right)$ & $25-45$ & $10-25$ & $5-10$ & $0-5$ & 0.058 & 0.039 & 0.049 \\
\hline $\begin{array}{l}\text { Contact zones of dissolvable and } \\
\text { insoluble rock }\left(U_{6}\right)\end{array}$ & $85-100$ & $70-85$ & $60-70$ & $50-60$ & 0.098 & 0.130 & 0.113 \\
\hline Layer and interlayer fissures $\left(U_{7}\right)$ & $85-100$ & $70-85$ & $60-70$ & $50-60$ & 0.038 & 0.058 & 0.048 \\
\hline
\end{tabular}

Table 2 Measured values of factor indexes associated with water inrush in Jigongling Tunnel.

\begin{tabular}{|c|c|c|c|c|c|c|c|c|c|}
\hline \multirow[b]{2}{*}{ Sample } & \multirow[b]{2}{*}{ Mileage location in Jigongling Tunnel } & \multicolumn{7}{|c|}{ Measured value of factor indexes } & \multirow{2}{*}{$\begin{array}{lr}\text { Actual water } \\
\text { inrush risk } \\
\text { levels }\end{array}$} \\
\hline & & $U_{1}$ & $U_{2}$ & $U_{3}$ & $U_{4}$ & $U_{5}$ & $U_{6}$ & $U_{7}$ & \\
\hline 1 & $\mathrm{~K} 19+240-\mathrm{K} 19+450$ & 90 & 75 & 75 & $20 \%$ & $13^{\circ}$ & 85 & 80 & III \\
\hline 2 & $\mathrm{~K} 19+450-\mathrm{K} 19+500$ & 80 & 60 & 75 & $40 \%$ & $16^{\circ}$ & 70 & 65 & II \\
\hline 3 & $\mathrm{~K} 19+500-\mathrm{K} 19+760$ & 75 & 60 & 75 & $40 \%$ & $16^{\circ}$ & 70 & 65 & II \\
\hline 4 & $\mathrm{~K} 19+760-\mathrm{K} 19+800$ & 60 & 60 & 75 & $40 \%$ & $13^{\circ}$ & 70 & 65 & II \\
\hline 5 & $\mathrm{~K} 19+800-\mathrm{K} 20+180$ & 55 & 65 & 75 & $30 \%$ & $13^{\circ}$ & 80 & 70 & II \\
\hline
\end{tabular}




\subsubsection{Evaluation results and validation of MFICM}

According to the level criteria listed in Table 1 and cloud model theory introduced in Section 3 , it is not difficult to obtain the three numerical characteristic parameters $(E x, E n$, and $H e)$ of the MFICM with seven evaluation indexes and four water inrush risk levels using Eqs. (11)-(13), as listed in Table 3. Then, a seven-dimensional finite interval cloud is generated based on a forward cloud generator via a MATLAB code. Since the rendering of seven-dimensional finite interval clouds cannot be realized using current technology, a two-dimensional finite interval cloud responding to the formation lithology and strata inclination is obtained to have a clear insight into the MFICM (seen Fig. 5).

Table 3 Numerical parameters of the MFICM for prediction of water inrush.

\begin{tabular}{ccccccccc}
\hline Risk levels & Numerical parameters & $U_{1}$ & $U_{2}$ & $U_{3}$ & $U_{4}$ & $U_{5}$ & $U_{6}$ & $U_{7}$ \\
\hline \multirow{3}{*}{ I } & $E x$ & 92.5 & 92.5 & 75 & 70 & 35 & 92.5 & 92.5 \\
& $E n$ & 30.833 & 30.833 & 25 & 23.333 & 11.667 & 30.833 & 30.833 \\
& $H e$ & 0.1 & 0.1 & 0.05 & 0.04 & 0.01 & 0.1 & 0.1 \\
\hline \multirow{2}{*}{ II } & $E x$ & 77.5 & 77.5 & 45 & 50 & 17.5 & 77.5 & 77.5 \\
& En & 30.833 & 30.833 & 25 & 23.333 & 11.667 & 30.833 & 30.833 \\
& He & 0.1 & 0.1 & 0.05 & 0.04 & 0.01 & 0.1 & 0.1 \\
\hline \multirow{3}{*}{ III } & Ex & 65 & 65 & 20 & 30 & 7.5 & 65 & 65 \\
& En & 30.833 & 30.833 & 25 & 23.333 & 11.667 & 30.833 & 30.833 \\
& He & 0.1 & 0.1 & 0.05 & 0.04 & 0.01 & 0.1 & 0.1 \\
\hline \multirow{2}{*}{ IV } & Ex & 55 & 55 & 5 & 10 & 2.5 & 55 & 55 \\
& En & 30.833 & 30.833 & 25 & 23.333 & 11.667 & 30.833 & 30.833 \\
& $H e$ & 0.1 & 0.1 & 0.05 & 0.04 & 0.01 & 0.1 & 0.1 \\
\hline
\end{tabular}




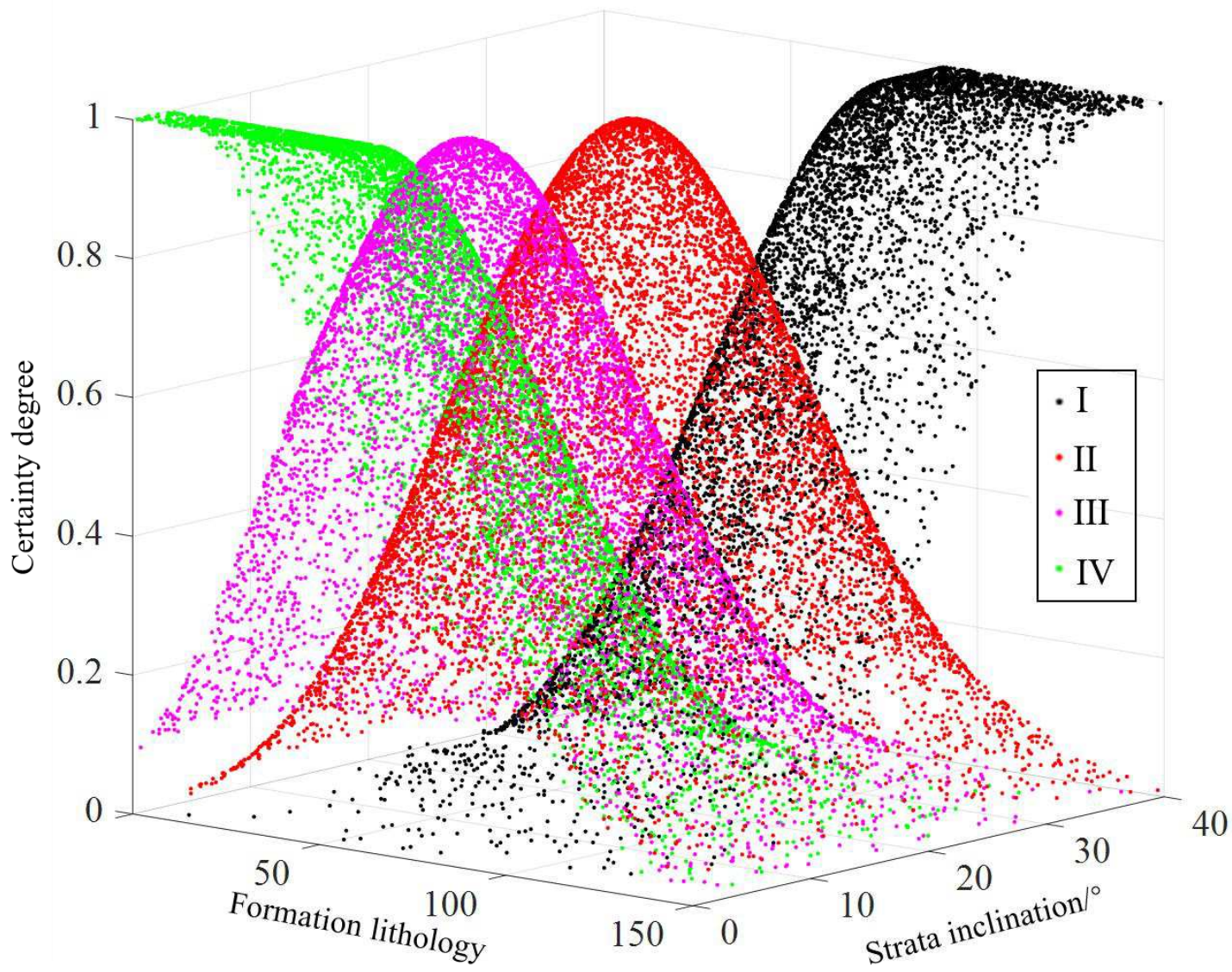

Fig. 5 The two-dimensional finite interval cloud for indexes of the formation lithology and strata inclination.

Finally, according to Eq. (15), a comprehensive certainty degree of the water inrush risk level for the five samples is obtained with the comprehensive index weight vector of $W=\{0.167,0.350$, $0.176,0.097,0.049\}$ and the measured values (see Table 2), and the water inrush risk evaluation level is determined using MFICM based on the principle of maximum membership (Eq. (16)), as shown in Table 4 . For sample 1 , the comprehensive certainty degree concerning level $I\left(C_{1}\right)$ is 0.5812, that for level II $\left(\mathrm{C}_{2}\right)$ is 0.6874 , that for level III $\left(\mathrm{C}_{3}\right)$ is 0.7952 and that for level IV $\left(\mathrm{C}_{4}\right)$ is 0.3796. Therefore, the water inrush risk of sample 1 is level III that is in a low risk situation. The risk levels of the remaining samples (2 to 5) are all level II (moderate risk), and the corresponding maximum comprehensive certainty degree are $0.8186,0.8186,0.7947$, and 0.7857 , respectively. In summary, the evaluation results of the five samples based on MFICM are level III, II, II, II, and II, 
respectively, which are is in agreement with the water inrush risk level observed in the field (Fig. 6). Those indicate that the MFICM proposed in the present study is reasonable and effective for predicting water inrush risk levels.

Taking sample 3 (mileage of K19+500-K19+760) as example, Fig. 7 shows that the certainty degree of water inrush belonging to different levels varies with varied parameter value of 7 indexes. As the index value increases, the certainty of level I first increases and then stabilizes, while level IV, whose certainty first stabilizes and then decreases, is just the opposite. As for level II and III, the certainty exhibits a tendency of increasing first and then decreasing. These descriptions are consistent with the cloud diagrams shown in Fig. 5. Additionally, as shown in Fig. 7 , the certainty degree of water inrush risk level is more sensitive to the value of unfavorable geological conditions $\left(U_{2}\right)$ and groundwater level $\left(U_{3}\right)$ in comparison with that of the rest of indexes, which implies that the variation in the index parameters of the unfavorable geological conditions and groundwater level exhibits a significant impact on the risk level of water inrush in tunneling. The certainty degrees relative to level I to IV for sample 3 are $0.6597,0.8186,0.6299$ and 0.4240 , respectively, and these values (i.e., blue dotted line) are almost close to the maximum certainty when the value of each index changes. Obviously, the risk level of water inrush for sample 3 belongs to level II.

Additionally, to further verify the reliability and validity of this proposed approach, comparisons of the evaluation results from the MFICM method, attribute mathematical method (Li et al. 2013a, 2013b), one-dimensional normal cloud method (Wang et al. 2016b), and set pair method (Wang et al. 2017) are made listed in Table 4. Based on one-dimensional normal cloud method, the comprehensive certainty degrees of level II and level III for sample 1 are 0.4038 and 
0.4741 , respectively. The two values are very close which cause that it is not conducive to accurately judging the risk level of water inrush. Similarly, in attribute mathematical method, the comprehensive certainty degrees of level I and level II for sample 2 and 3 are 0.378 and 0.351 , respectively, and that of level I and level II for sample 4 are respectively 0.451 and 0.435 . However, these phenomena are not observed in Table 4 using MFICM. For example, the comprehensive certainty degrees of level II and level III for sample 2 are 0.8186 and 0.6230 , respectively, which is easy to determine that the water inrush has a risk with level II. It can be concluded that the accuracy of the MFICM may be superior to one-dimensional normal cloud and attribute mathematical method. The reason for the above results may be attributed to the following facts: i) a normal distribution with a finite interval, which better characterizes the actual distribution of the indicators, is considered in the MFICM. ii) the MFICM is a comprehensive model determined by integrating multiple factors into one-dimensional variables; thus, it can reflect the interaction between indicators, which is also consistent with the characteristics of various geological disasters that are a complex system with multiple indexes interacting. iii) the cloud model itself is a two-way conversion cognitive model that realizes qualitative concept and quantitative data, so the MFICM can convert the ambiguity and randomness that arises in the prediction process of various geological disasters into a quantitative comprehensive certainty to accurately reflect the uncertainty of disaster prediction.

Table 4 Evaluation results and comparison with other previous methods.

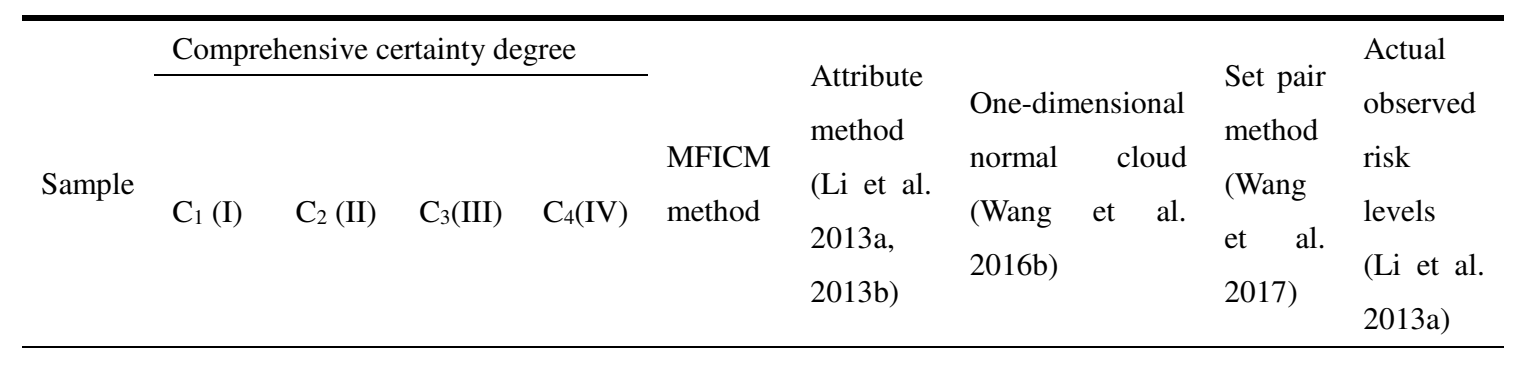




\begin{tabular}{llllllllll}
\hline 1 & 0.5812 & 0.6874 & 0.7952 & 0.3796 & III & III & III & III & III \\
2 & 0.6685 & 0.8186 & 0.6230 & 0.4157 & II & II & II & II & II \\
3 & 0.6597 & 0.8186 & 0.6299 & 0.4240 & II & II & II & II & II \\
4 & 0.6041 & 0.7947 & 0.6389 & 0.4439 & II & II & II & II & II \\
5 & 0.5974 & 0.7857 & 0.6353 & 0.4467 & II & II & II & II & II \\
\hline
\end{tabular}
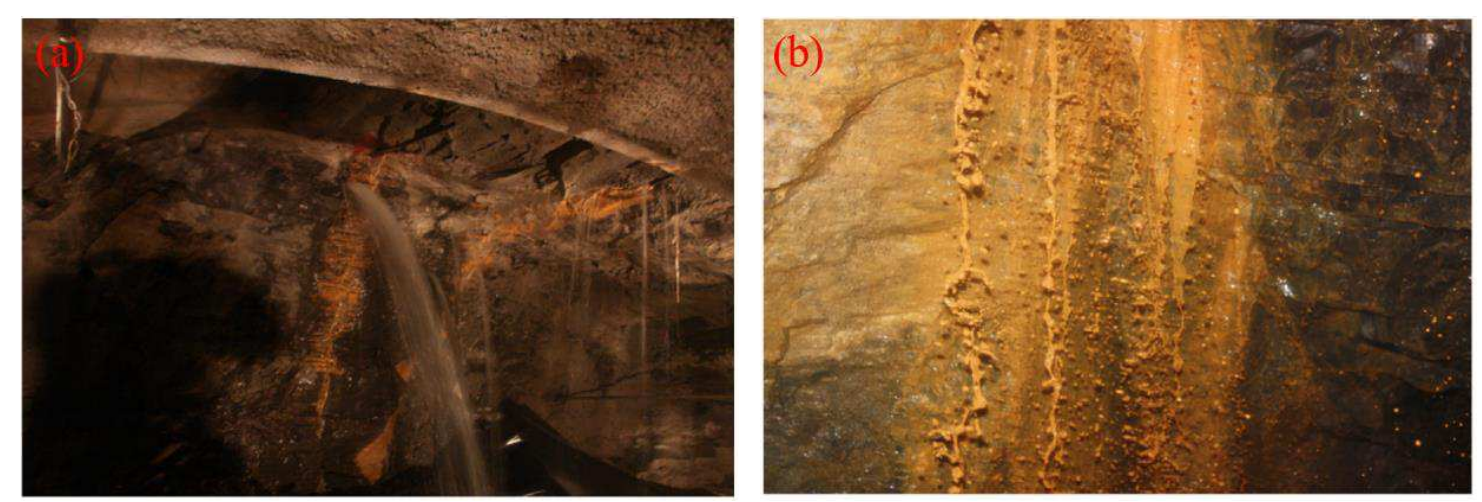

Fig. 6 Water inrush at K19+512 (a) and K19+536 (b) [belonging to sample 3] in Jigongling

Tunnel (Li et al. 2013a).

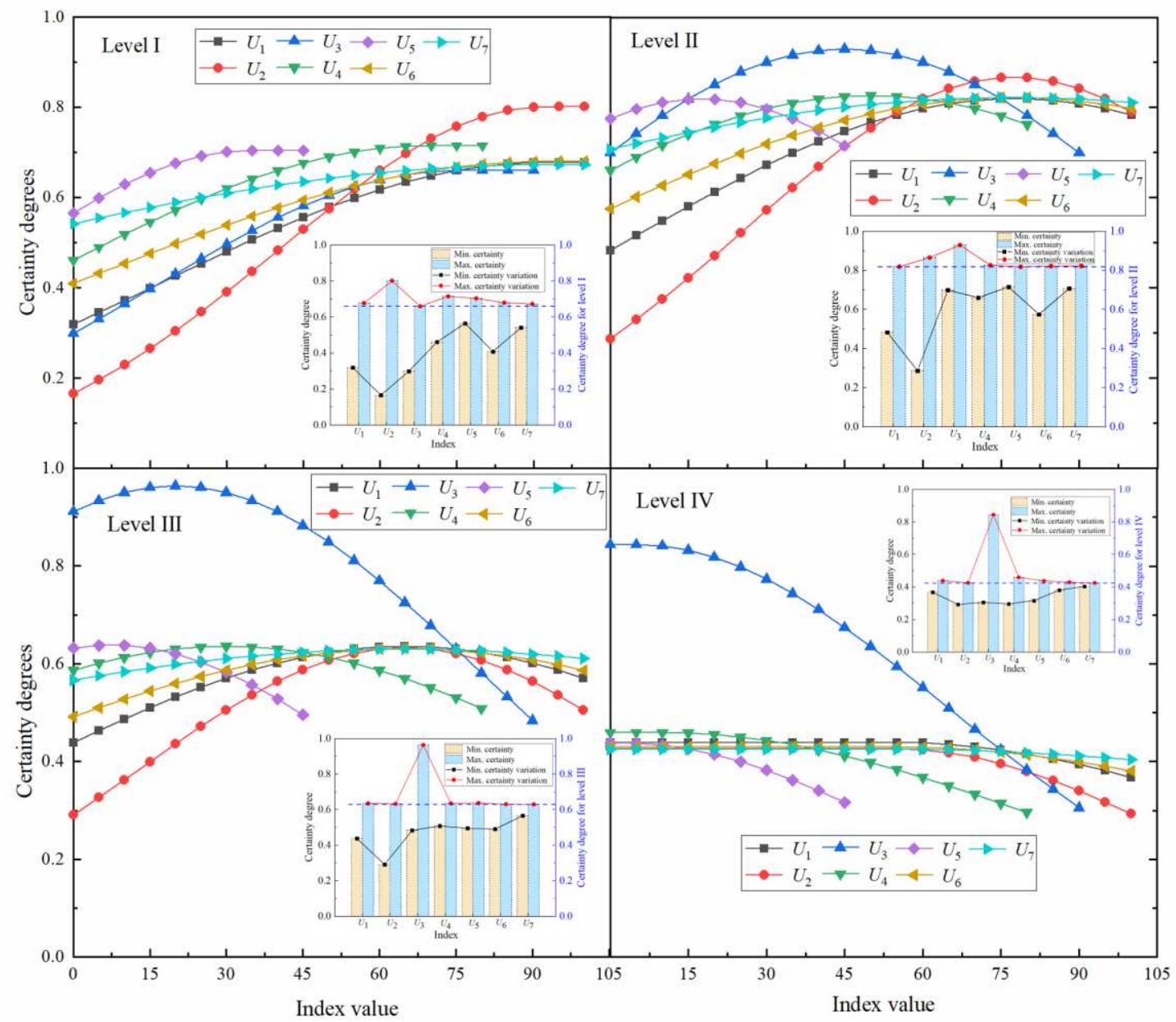

Fig. 7 Effect of each index value variation on each water inrush risk level. 


\subsection{Case 2: Application of MFICM to rock burst risk assessment in deeply buried}

underground engineering

\subsubsection{Evaluation system and case data}

Rock bursts have become a grave challenge in deep mining and underground engineering, and an accurate prediction of rock bursts is required to ensure safety (Liu et al. 2020). According to the internal and external conditions of rock bursts and previous studies on rock bursts (Wang and Park 2001; Feng et al. 1996; Russenes 1974), there are four key factors, namely, the stress coefficient $\left(\sigma_{\theta} / \sigma_{c}\right)$, brittle coefficient $\left(\sigma_{c /} \sigma_{t}\right)$, elastic deformation energy $\left(W_{e t}\right)$, and rock integrity coefficient $\left(K_{v}\right)$, which are regarded as evaluation indexes in this case. The risk associated with rock burst is also separated into four levels presented by Level I $<$ Level II $<$ Level III $<$ Level IV, which is opposite to the order of the water inrush disaster levels mentioned above. Measured data of 20 rock burst engineering cases occurring in China and abroad are used in the present study. The level criteria of rock burst and 20 groups of measured values of factor indexes are presented in Table 5 and Table 6, respectively (Wang et al. 1998; Zhou et al. 2013).

\subsubsection{Weight of evaluation indexes}

Regardless of which evaluation methods are used, such as AHP-fuzzy (Kubler et al. 2016), grey correlation-entropy method (Gao et al. 2017) and efficacy coefficient model (Qiu et al. 2013), it is important to accurately determine the weight of the evaluation index for the final evaluation results. Therefore, in the present study, a combination weight method, which considers a linear combination of the subjective weight obtained from the AHP and the objective weight obtained from the PCA, is adopted to confirm the weight of the evaluation indexes.

In light of the AHP steps introduced in Section 2.1, the judgment matrix $P_{1}$ of Eq. (17) about 
the four factor indexes is first established, and the subjective weight vector $w_{i}=\{0.4236,0.2270$, $0.2270,0.1223\}$, and parameters $\lambda_{\max }=4.0104$ and $C R=0.0039<0.1$ (which meet the consistency requirement) are obtained using Eqs. (1)-(3).

Analogously, based on the PCA steps described in Section 2.2 and 20 groups of measured data of the evaluation indexes listed in Table 6, the weights are calculated using Eqs. (4)-(8). The calculation and analysis procedures are realized by MATLAB code, which can easily calculate the correlation coefficient matrix, principal component variance, and component matrix, as presented in Tables 7-9. Therefore, the objective weight vector is $w_{j}=\{0.3542,0.2952,0.1675,0.1831\}$. Finally, according to the determination method over the combination weight used in the study of Li et al. (2013a), i.e., both of the weight coefficients $\varphi_{1}$ and $\varphi_{2}$ equal 0.5 , the combination weight vector $W=\{0.3889,0.2611,0.1973,0.1527\}$ in this case is determined by Eq. (9), as shown in Table 5.

$$
P_{1}=\left[\begin{array}{ccccc} 
& U_{1} & U_{2} & U_{3} & U_{4} \\
U_{1} & 1 & 2 & 2 & 3 \\
U_{2} & 1 / 2 & 1 & 1 & 2 \\
U_{3} & 1 / 2 & 1 & 1 & 2 \\
U_{4} & 1 / 3 & 1 / 2 & 1 / 2 & 1
\end{array}\right]
$$

Table 5 Factor indexes and level criteria of rock bursts.

\begin{tabular}{|c|c|c|c|c|c|c|c|}
\hline \multirow{2}{*}{$\begin{array}{l}\text { Factor indexes associated with } \\
\text { rock burst }\end{array}$} & \multicolumn{4}{|c|}{ The risk levels of rock burst (low $\rightarrow$ high) } & \multirow{2}{*}{$w_{i}$} & \multirow{2}{*}{$w_{j}$} & \multirow{2}{*}{$V$} \\
\hline & I & II & III & IV & & & \\
\hline Stress coefficient $\left(\sigma_{\theta} / \sigma_{c}\right), U_{1}$ & $0.1-0.3$ & $0.3-0.5$ & $0.5-0.7$ & $0.7-0.9$ & 0.4236 & 0.3542 & 0.3889 \\
\hline Brittle coefficient $\left(\sigma_{c /} \sigma_{t}\right), U_{2}$ & $40.0-2$ & $26.7-40.0$ & $14.5-26.7$ & $9.0-14.5$ & 0.2270 & 0.2952 & 0.2611 \\
\hline $\begin{array}{l}\text { Elastic deformation energy }\left(W_{e t}\right) \text {, } \\
U_{3}\end{array}$ & $1.0-2.0$ & $2.0-4.0$ & $4.0-6.0$ & $6.0-9.0$ & 0.2270 & 0.1675 & 0.1973 \\
\hline Rock integrity coefficient $\left(K_{v}\right), U_{4}$ & $0.50-0.55$ & $0.55-0.65$ & $0.65-0.75$ & $0.75-0.88$ & 0.1223 & 0.1831 & 0.1527 \\
\hline
\end{tabular}

Note: $\sigma \theta$, tangential stress; $\sigma_{c}$, uniaxial compressive strength; $\sigma_{t}$, uniaxial tensile strength. 
Table 6 Measured value of factor indexes of 20 samples.

\begin{tabular}{|c|c|c|c|c|c|c|c|c|c|}
\hline \multirow{2}{*}{ Samples } & \multicolumn{4}{|c|}{ Measured factor indexes } & \multirow{2}{*}{ Samples } & \multicolumn{4}{|c|}{ Measured factor indexes } \\
\hline & $U_{1}\left(\sigma_{\theta} / \sigma_{c}\right)$ & $U_{2}\left(\sigma_{c /} \sigma_{t}\right)$ & $U_{3}\left(W_{e t}\right)$ & $U_{4}\left(K_{v}\right)$ & & $U_{1}\left(\sigma_{\theta} / \sigma_{c}\right)$ & $U_{2}\left(\sigma_{c /} \sigma_{t}\right)$ & $U_{3}\left(W_{e t}\right)$ & $U_{4}\left(K_{v}\right)$ \\
\hline 1 & 0.58 & 13.2 & 6.3 & 0.79 & 11 & 0.42 & 21.7 & 4.5 & 0.67 \\
\hline 2 & 0.45 & 17.5 & 5.1 & 0.68 & 12 & 0.39 & 21.7 & 5.0 & 0.73 \\
\hline 3 & 0.39 & 20.9 & 4.6 & 0.65 & 13 & 0.10 & 23.0 & 4.7 & 0.52 \\
\hline 4 & 0.20 & 41.0 & 1.7 & 0.50 & 14 & 0.44 & 26.9 & 5.5 & 0.78 \\
\hline 5 & 0.66 & 13.2 & 6.8 & 0.82 & 15 & 0.81 & 18.5 & 3.8 & 0.68 \\
\hline 6 & 0.38 & 17.5 & 4.5 & 0.56 & 16 & 0.41 & 29.4 & 7.3 & 0.64 \\
\hline 7 & 0.41 & 29.7 & 3.3 & 0.64 & 17 & 0.59 & 22.9 & 5.0 & 0.63 \\
\hline 8 & 0.11 & 31.2 & 3.7 & 0.71 & 18 & 0.54 & 17.5 & 6.6 & 0.61 \\
\hline 9 & 0.23 & 27.8 & 3.9 & 0.59 & 19 & 0.38 & 19.7 & 5.0 & 0.69 \\
\hline 10 & 0.53 & 15.0 & 6.5 & 0.70 & 20 & 0.38 & 28.4 & 5.0 & 0.58 \\
\hline
\end{tabular}

Table 7 The correlation coefficient matrix of evaluation indexes.

\begin{tabular}{lllll}
\hline & $U_{1}$ & $U_{2}$ & $U_{3}$ & $U_{4}$ \\
\hline$U_{1}$ & 1 & -0.6289 & 0.4495 & 0.5134 \\
$U_{2}$ & -0.6289 & 1 & -0.6311 & -0.5071 \\
$U_{3}$ & 0.4495 & -0.6311 & 1 & 0.5027 \\
$U_{4}$ & 0.5134 & -0.5071 & 0.5027 & 1 \\
\hline
\end{tabular}

Table 8 The principal component variance.

\begin{tabular}{llll}
\hline Component & $\lambda$ & $f(i)(\%)$ & $F(b)(\%)$ \\
\hline 1 & 2.6201 & 65.503 & 65.503 \\
2 & 0.5527 & 13.818 & 79.320 \\
3 & 0.5274 & 13.185 & 92.505 \\
4 & 0.2998 & 7.495 & 100 \\
\hline
\end{tabular}

Table 9 The component matrix of principal components.

\begin{tabular}{lllll}
\hline Component & $U_{1}$ & $U_{2}$ & $U_{3}$ & $U_{4}$ \\
\hline 1 & -0.8012 & 0.8634 & -0.7982 & -0.7718 \\
2 & -0.4590 & -0.0926 & 0.5450 & -0.1908 \\
3 & -0.2863 & 0.2890 & 0.0185 & 0.6013 \\
\hline
\end{tabular}

\subsubsection{Evaluation results and validation of MFICM}

Based on the calculation process of the previous case described in Section 4.1.3, the results of rock burst prediction of 20 typical engineering samples are obtained, as shown in Table 10. It can be seen from Table 10 that the prediction results from MFICM method are generally identical to the actual rock burst levels, which testifies the availability of the proposed method. Meanwhile, a 
comparison of the predicted results of the MFICM method, entropy-cloud model (Zhou et al. 2016), multidimensional normal cloud model (Guo et al. 2018) and RS-TOPSIS method (Zhou et al. 2013) is made. Obviously, there is reasonably good agreement among the predicted results from the MFICM method, entropy-cloud model, multidimensional normal cloud model and the RS-TOPSIS method. These results further prove that the MFICM method in this work is validated for application to the risk evaluation of rock bursts in deeply buried underground engineering projects.

\subsubsection{Risk prediction of rock burst of the diversion tunnel in Jinping II hydropower station}

Jinping II hydropower station, located in Liangshan Prefecture, Sichuan Province, is the largest hydropower on Yalong River. Seven diversion tunnels with the maximum buried depth of $2525 \mathrm{~m}$ are arranged in parallel, and the total length is about $16.7 \mathrm{~km}$. The characteristics of large buried depth, long tunnel length and high geostress are prominently reflected in the diversion tunnel group of Jinping II hydropower station. Various geological problems such as surrounding rock failure are encountered in tunneling. In particular, rock burst disasters occur frequently. Therefore, it is necessary to conduct a prediction on rock burst of the diversion tunnels to take corresponding measures to ensure safety.

Based on the MFICM proposed in this study, five sections of a diversion tunnel of Jinping II hydropower station are analyzed. The index measured data and prediction results of each section of a diversion tunnel are shown in Table 11 (Zhang et al. 2020). It can be seen from Table 11 that the prediction results of the MFICM exhibit extremely good agreement with the actual situations and better accuracy than other methods. In the construction section of $8000-16200 \mathrm{~m}$, the rock mass possesses perfect high stress conditions causing rock burst susceptibility. Fig. 8 shows the 
site rock burst conditions in Jinping II hydropower station. These results indicate that the effectiveness and feasibility of MFICM reflect in the classification and prediction of rock burst intensity.
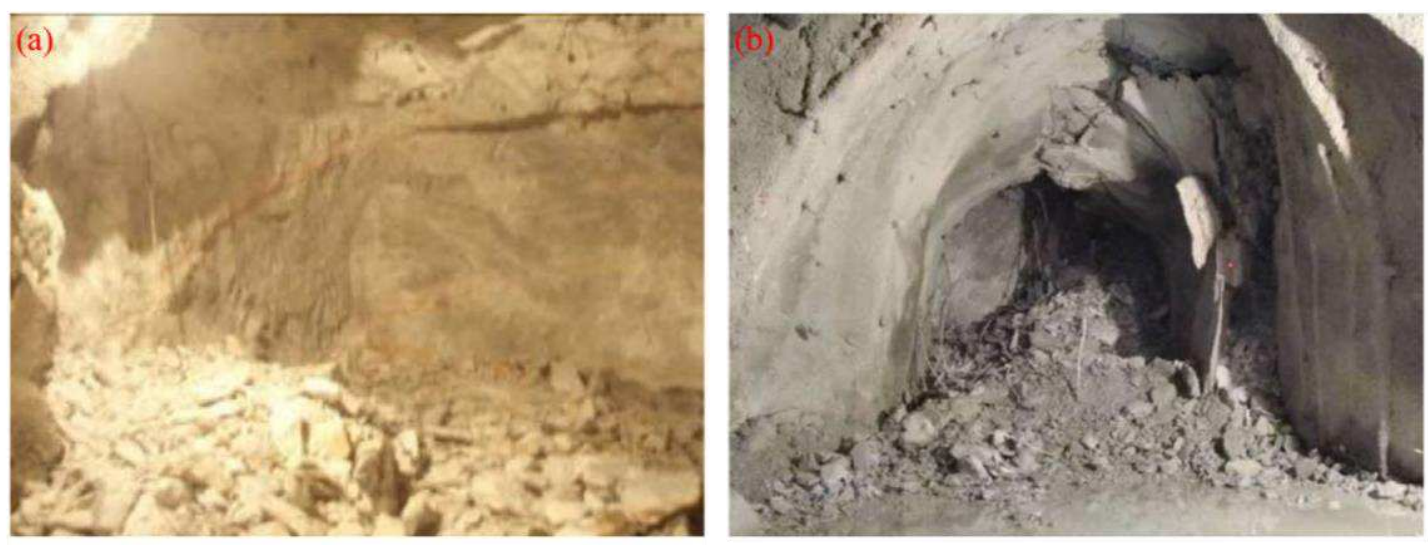

Fig. 8 Rock burst conditions of the diversion tunnels at BK6+754 (a) and at AK9+485 490 (b) of Jinping II hydropower station (Zhang et al. 2020). 
Table 10 Evaluation results and comparison with other previously used methods.

\begin{tabular}{|c|c|c|c|c|c|c|c|c|c|}
\hline \multirow{2}{*}{ Samples } & \multicolumn{4}{|c|}{ Comprehensive certainty degree } & \multirow{2}{*}{ MFICM method } & \multirow{2}{*}{$\begin{array}{l}\text { Actual levels } \\
\text { (Zhou et al. 2013) }\end{array}$} & \multirow{2}{*}{$\begin{array}{l}\text { Entropy-cloud model } \\
\text { (Zhou et al. 2016) }\end{array}$} & \multirow{2}{*}{$\begin{array}{l}\text { Multidimensional } \\
\text { normal cloud } \\
\text { (Guo et al. 2018) }\end{array}$} & \multirow{2}{*}{$\begin{array}{l}\text { RS-TOPSIS } \\
\text { (Zhou et al. 2013) }\end{array}$} \\
\hline & $\mathrm{C}_{1}(\mathrm{I})$ & $\mathrm{C}_{2}$ (II) & $\mathrm{C}_{3}(\mathrm{III})$ & $\mathrm{C}_{4}(\mathrm{IV})$ & & & & & \\
\hline 1 & 0.2458 & 0.5686 & 0.8510 & 0.9309 & IV & IV & IV & IV & IV \\
\hline 2 & 0.4428 & 0.7806 & 0.9316 & 0.6212 & III & III & III & III & III \\
\hline 3 & 0.5629 & 0.8652 & 0.8978 & 0.5021 & III & III & III & III & III \\
\hline 4 & 0.9979 & 0.8282 & 0.3915 & 0.1103 & I & I & I & I & I \\
\hline 5 & 0.1849 & 0.4814 & 0.8952 & 0.9375 & IV & IV & III IV & IV & IV \\
\hline 6 & 0.5244 & 0.8453 & 0.8155 & 0.4834 & II & II & II & II $\sim$ III & II \\
\hline 7 & 0.9879 & 0.7430 & 0.8145 & 0.3885 & I & I & II* & $\mathrm{II}^{*}$ & I \\
\hline 8 & 0.8239 & 0.7695 & 0.4572 & 0.1597 & I & I & II* & $\mathrm{I} \sim \mathrm{II}$ & II* \\
\hline 9 & 0.8914 & 0.7883 & 0.6349 & 0.2610 & I & I & I & I & I \\
\hline 10 & 0.2944 & 0.6263 & 0.9335 & 0.7843 & III & III & III & III & III \\
\hline 11 & 0.5580 & 0.8776 & 0.9170 & 0.5303 & III & III & III & III & III \\
\hline 12 & 0.5382 & 0.8448 & 0.8807 & 0.5243 & III & III & III & III & III \\
\hline 13 & 0.6985 & 0.6650 & 0.4728 & 0.1854 & I & I & I & I & I \\
\hline 14 & 0.5298 & 0.8517 & 0.8962 & 0.5584 & III & III & III & III & III \\
\hline 15 & 0.2132 & 0.5270 & 0.8603 & 0.7737 & III & III & III & III & III \\
\hline 16 & 0.4664 & 0.7865 & 0.7483 & 0.5108 & II & II & II & II & III* \\
\hline 17 & 0.4129 & 0.7892 & 0.9912 & 0.7131 & III* & II & III* & III* & II \\
\hline 18 & 0.3180 & 0.8236 & 0.8710 & 0.7634 & III* & II & II III & II III & III* \\
\hline 19 & 0.5212 & 0.8236 & 0.8710 & 0.5199 & III & III & III & III & III \\
\hline 20 & 0.6617 & 0.9246 & 0.8245 & 0.4328 & II & II & II & II & II \\
\hline
\end{tabular}

Note: Superscript $*$ denotes misjudgment. 
Table 11 The index measured data and prediction results of each section of a diversion tunnel in Jinping II hydropower station.

\begin{tabular}{|c|c|c|c|c|c|c|c|c|}
\hline Section (m) & $\sigma_{\theta} / \sigma_{c}$ & $\sigma_{c /} \sigma_{t}$ & $W_{e t}$ & $K_{v}$ & MFICM method & Comprehensive geological prediction method & Gray system relevance degree method & Actual rock burst level \\
\hline $8000-10000$ & 1.08 & 17.7 & 3.2 & 0.7 & III & II III & III & III (moderate) \\
\hline $10000-13500$ & 1.13 & 17.7 & 3.2 & 0.45 & II & II $\sim \mathrm{III}$ & II $\sim$ III & II (weak) III (moderate) \\
\hline $13500-15000$ & 0.86 & 16.7 & 3.2 & 0.48 & II & II & II & II (weak) \\
\hline $15000-16200$ & 0.62 & 16 & 3.3 & 0.37 & III & III & I & III (moderate) \\
\hline $16200-17230$ & 0.31 & 15.9 & 2.2 & 0.4 & I & I & I & I (none) \\
\hline
\end{tabular}




\subsection{Case 3: Application of MFICM to collapse risk assessment in Qiyueshan Tunnel}

\subsubsection{Evaluation system and case data}

Tunnel collapse is essentially a process of instability and failure of surrounding rock of tunnels, which is attributed not only to natural factors, i.e., the stress conditions in situ, existence of cracks and earthquake effects, but also to human factors, i.e., the construction plan, management level and support design. There are great uncertainties in tunneling, such as groundwater level and rock strength difference, which may lead to a rather complicated problem in predicting the possibility of tunnel collapse.

Qiyueshan tunnel, located in Hubei Province, a typical karst tunnel, is in this work used as the research object to discuss the reliability of MFICM for predicting collapse. A specific introduction about Qiyueshan tunnel can refer to Wang et al. (2019b). Seven factor indexes, defective geological, tunnel depth, construction measures, rock mass integrity, rock strength, rock inclination and water table, are chosen as the evaluation indexes of tunnel collapse to predict the collapse risk level. The risk levels of tunnel collapse, identical to the water inrush disaster presented in Case 1, are classified into four grades: Level I > Level II > Level III > Level IV, and the level criteria relative to collapse is shown in Table 12 (Gao et al. 2017).

\subsubsection{Weight of evaluation indexes}

Similarly, an establishment of the judgment matrix $P_{2}$ (see Eq. (18)) of these seven evaluation indexes is performed according to the AHP method. Therefore, in this case, using Eqs. (1)-(3), all of the subjective weight vectors $w_{i}=\{0.2757,0.0617,0.0722,0.1279,0.2479,0.0370,0.1776\}$, $\lambda_{\max }=7.6947$, and $C R=0.0851<0.1$ that satisfy the consistency requirement are calculated, as shown in Table 12. Moreover, the entropy weight method introduced in the study of Gao et al. 
(2017) is used to confirm the objective weight in this case instead of the PCA method mentioned in the present work. That is, the objective weights $\left(w_{j}\right)$ of the evaluation indexes are the same as the values given in the previous literature. As explained in Section 4.1.2, the limited sample data cannot perform the function of the PCA method. Finally, based on Eq. (9), the combination weight vector $W=\{0.1853,0.0918,0.1448,0.1306,0.1863,0.0951,0.1662\}$ is calculated.

$$
P_{2}=\left[\begin{array}{cccccccc} 
& U_{1} & U_{2} & U_{3} & U_{4} & U_{5} & U_{6} & U_{7} \\
U_{1} & 1 & 5 & 7 & 3 & 1 & 6 & 1 \\
U_{2} & 1 / 5 & 1 & 1 / 2 & 1 / 3 & 1 / 2 & 3 & 1 / 4 \\
U_{3} & 1 / 7 & 2 & 1 & 1 / 2 & 1 / 5 & 4 & 1 / 3 \\
U_{4} & 1 / 3 & 3 & 2 & 1 & 1 / 2 & 6 & 1 / 2 \\
U_{5} & 1 & 2 & 5 & 2 & 1 & 3 & 3 \\
U_{6} & 1 / 6 & 1 / 3 & 1 / 4 & 1 / 6 & 1 / 3 & 1 & 1 / 3 \\
U_{7} & 1 & 4 & 3 & 2 & 1 / 3 & 3 & 1
\end{array}\right]
$$

Table 12 Factor indexes and level criteria of collapse in tunnels.

\begin{tabular}{|c|c|c|c|c|c|c|c|}
\hline \multirow{2}{*}{$\begin{array}{l}\text { Factor indexes associated with } \\
\text { collapse }\end{array}$} & \multicolumn{4}{|c|}{ The risk levels of collapse } & \multirow[b]{2}{*}{$w_{i}$} & \multirow[b]{2}{*}{$w_{j}$} & \multirow[b]{2}{*}{$W$} \\
\hline & $\begin{array}{l}\text { I } \\
\text { (high) }\end{array}$ & $\begin{array}{l}\text { II } \\
\text { (moderate) }\end{array}$ & III (low) & $\begin{array}{l}\text { IV (very } \\
\text { low) }\end{array}$ & & & \\
\hline Defective geological $\left(U_{1}\right)$ & $0-60$ & $60-70$ & $70-85$ & $85-100$ & 0.2757 & 0.0949 & 0.1853 \\
\hline Tunnel depth $\left(U_{2}\right)$ & $0-10$ & $10-25$ & $25-50$ & $50-80$ & 0.0617 & 0.1219 & 0.0918 \\
\hline Construction measures $\left(U_{3}\right)$ & $0-70$ & $70-80$ & $80-90$ & $90-100$ & 0.0722 & 0.2174 & 0.1448 \\
\hline Rock mass integrity $\left(U_{4}\right)$ & $0-0.15$ & $0.15-0.35$ & $0.35-0.55$ & $0.55-0.8$ & 0.1279 & 0.1333 & 0.1306 \\
\hline Rock strength $\left(U_{5}\right)$ & $0-20$ & $20-30$ & $30-40$ & $40-50$ & 0.2479 & 0.1246 & 0.1863 \\
\hline Rock inclination angle $\left(U_{6}\right)$ & $0-20$ & $20-30$ & $30-40$ & $40-45$ & 0.0370 & 0.1532 & 0.0951 \\
\hline Water table $\left(U_{7}\right)$ & $0-10$ & $10-20$ & $20-30$ & $30-40$ & 0.1776 & 0.1547 & 0.1662 \\
\hline
\end{tabular}

\subsubsection{Evaluation results and validation of MFICM}

To verify the MFICM, seven measured samples (Gao et al. 2017) collected from Qiyueshan tunnel are selected and evaluated regrading collapse, as listed in Table 13. From Table 13, the evaluation results from the MFICM are in good agreement with the grey correlation-entropy method results. For sample 3 (YK52+940-YK53+107), the comprehensive certainty degree belonging to level $\mathrm{I}\left(\mathrm{C}_{1}\right)$ is 0.3248 , that for level II $\left(\mathrm{C}_{2}\right)$ is 0.6901 , that for level III $\left(\mathrm{C}_{3}\right)$ is 0.6526 
and that for level IV $\left(\mathrm{C}_{4}\right)$ is 0.4450 . According to the principle of maximum membership, the collapse level in this mileage is level II belonging to a moderate risk level. When the tunnel is excavated to the mileage YK52+965, a sudden collapse appears, as shown in Fig. 9. The result of the field observation is coincided with the result predicted by the proposed MFICM. These comparison and field observation imply that the MFICM is reasonable and can feasibly predict the tunnel collapse probability.

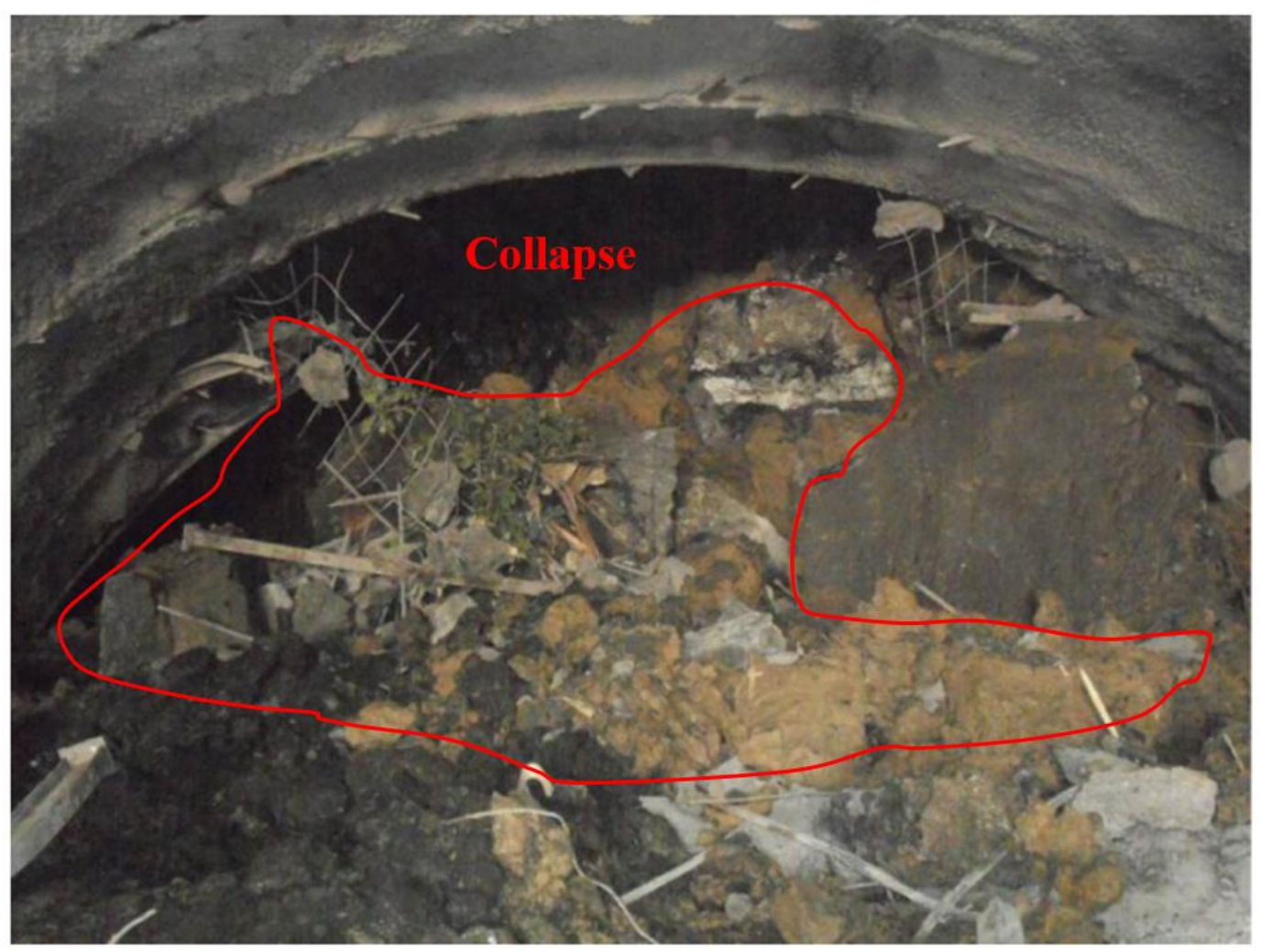

Fig. 9 A collapse appeared at the mileage YK52+965 in Qiyueshan Tunnel (Gao et al. 2017). 
Table 13 Results of the evaluation sample using MFICM and comparison with the grey correlation-entropy method results.

\begin{tabular}{|c|c|c|c|c|c|c|c|c|c|c|c|c|c|c|}
\hline \multirow{2}{*}{ Sample } & \multirow{2}{*}{$\begin{array}{l}\text { Mileage location } \\
\text { in Qiyueshan Tunnel }\end{array}$} & \multicolumn{7}{|c|}{ Measured value of factor indexes } & \multicolumn{4}{|c|}{ Comprehensive certainty degree } & \multirow{2}{*}{ MFICM method } & \multirow{2}{*}{$\begin{array}{l}\text { Grey correlation-entropy method } \\
\text { (Gao et al. 2017) }\end{array}$} \\
\hline & & $U_{1}$ & $U_{2}$ & $U_{3}$ & $U_{4}$ & $U_{5}$ & $U_{6}$ & $U_{7}$ & $\mathrm{C}_{1}(\mathrm{I})$ & $\mathrm{C}_{2}$ (II) & $\mathrm{C}_{3}(\mathrm{III})$ & $\mathrm{C}_{4}(\mathrm{IV})$ & & \\
\hline 1 & M1: YK52+900-YK52+905 & 83 & 10 & 85 & 0.35 & 28.9 & 8.0 & 30 & 0.3345 & 0.7628 & 0.7448 & 0.4195 & II & II \\
\hline 2 & M2: YK52+905-YK52+940 & 70 & 15 & 85 & 0.48 & 32.0 & 8.0 & 30 & 0.3121 & 0.7315 & 0.7804 & 0.4853 & III & III \\
\hline 3 & M3: YK52+940-YK53+107 & 54 & 30 & 78 & 0.73 & 26.8 & 10 & 20 & 0.3248 & 0.6901 & 0.6526 & 0.4450 & II & II \\
\hline 4 & M4: YK53+107-YK53+215 & 62 & 45 & 75 & 0.67 & 34.7 & 16 & 22 & 0.2671 & 0.6586 & 0.8211 & 0.6237 & III & III \\
\hline 5 & M5: YK53+215-YK53+372 & 76 & 55 & 85 & 0.62 & 47.8 & 25 & 22 & 0.1525 & 0.5494 & 0.8447 & 0.7996 & III & III \\
\hline 6 & M6: YK53+372-YK53+390 & 88 & 30 & 75 & 0.42 & 45.0 & 25 & 30 & 0.1984 & 0.6629 & 0.9003 & 0.7172 & III & III \\
\hline 7 & M7: YK53+390-YK53+393 & 79 & 15 & 85 & 0.38 & 42.5 & 25 & 30 & 0.2394 & 0.7297 & 0.8878 & 0.6153 & III & III \\
\hline
\end{tabular}




\section{Discussions}

To reduce the influence of subjective factors on the index weight, in this work, a linear weighted combination method, i.e., combining the subjective weight obtained from the AHP and the objective weight obtained from the PCA, is used to calculate the index weight. However, because the PCA method has requirements for sample size (Shafiullah and Al-Ruwaih 2020) and the number of samples collected for geological disaster cases is limited, only Case 2, with 20 rock burst samples, uses the PCA method to determine the objective weight of the indicators. Therefore, to make a better comparison between these three cases, more sample data associated with Case 1 (water inrush) and Case 3 (tunnel collapse) should be collected in future research. Additionally, according to the study of $\mathrm{Li}$ et al. (2013a), in Eq. (9), the subjective weight coefficient $\varphi_{1}$ is the same as the objective weight coefficient $\varphi_{2}$, both equal to 0.5 , which affects the accuracy of the evaluation results. Therefore, alternatives to the above method of Li et al. (2013a), such as the Delphi method (Dalkey and Helmer 1963; Okoli and Pawlowski 2004), the game theory method (Lai et al. 2015), the normalization of expert conclusions (Xu et al. 2011) and genetic algorithm (Anagnostopoulos and Mamanis 2011), may be taken into account in future research.

Additionally, as the MFICM has many merits, it still has some limitations, and further research is required in the future. In the present study, only the situation where the evaluation indicators obey the uniform distribution and the normal distribution is discussed, and importantly, the sum of the four levels of the calculated comprehensive certainty is not equal to 1 . Therefore, how to reasonably set the digital feature parameters of the MFICM to achieve a sum of the comprehensive certainty equal to 1 and how to better embed index weights into the MFICM should be further studied. Additionally, the application of the MFICM is still a preliminary attempt 
at the assessment of geological disasters. That is, the MFICM is in the preliminary stage of conceptualization and needs to be applied to the assessment of other geotechnical engineering issues, such as gas outbursts, floor water inrush, slope stability and rock mass quality classification, in the future.

\section{Conclusions}

In this work, a new method named MFICM is proposed for risk evaluation of three geological disasters encountered in the construction of underground engineering. A linear weighted combination of the subjective weight obtained by the AHP and the objective weight obtained by the PCA is used to determine the index weight. The primary conclusions are summarized herewith:

(1) The MFICM with three main numerical characteristic parameters offers a new notion to characterize actual features of uncertainty indexes in the finite interval and the classification criteria of interval values. Additionally, MFICM is comprehensive prediction model determined by integrating multiple factors into one-dimensional variables, which depicts the characteristics of geological disasters that are a complex system with multiple indexes interacting.

(2) Engineering applications have been conducted to validate the practicability and precision of the MFICM for the risk evaluation of geological disasters, namely, water inrush, rock burst and tunnel collapse, in underground engineering. These results show that the MFICM is verified to be useful and practical for the risk evaluation of geological disasters.

(3) The MFICM is a helpful means to achieve a conversion between qualitative concept and quantitative data via considering the built-in relation of all the indexes. Moreover, the proposed model shows good accuracy in predicting the risk levels of the three disasters, which implies that 
it may have a certain universality in disaster risk prediction. Therefore, it can be considered that MFICM method may provide a way of quantitative analysis for similar engineering problems.

\section{Availability of data, code and material:}

All data, models, or code that support the findings of this study are available from the corresponding author upon reasonable request.

Declarations of interest: None.

\section{Authors' contributions:}

T.H. Wu conceived and designed the research, wrote the paper and programmed with MATLAB software; Y.T. Gao drew the figures, collected and analyzed the data; Y. Zhou programmed with MATLAB software and contributed ideas concerning the structure and content of the article; H. Sun reviewed and edited the manuscript.

\section{Acknowledgements:}

The research was supported by the National Natural Science Foundation of China (Grant No. 51504016, 52004017), Fundamental Research Funds for the Central Universities (Grant No. FRF-BD-17-007A, FRF-TP-19-026A1), and the China Postdoctoral Science Foundation (Grant No. 2020M670138). The authors would like to express appreciation to the Editors and anonymous Reviewers for their valuable and constructive comments relevant to this manuscript.

\section{References}

Anagnostopoulos KP, Mamanis G (2011) The mean-variance cardinality constrained portfolio optimization problem: An experimental evaluation of five multiobjective evolutionary algorithms. 
Expert Syst Appl 38:14208-14217

Beard AN (2010) Tunnel safety, risk assessment and decision-making. Tunn Undergr Space Technol 25(1):91-94

Brown ET (2012) Risk assessment and management in underground rock engineering - an overview. J Rock Mech Geotech Eng 4(3):193-204

Cai W, Dou LM, Zhang M, Cao WZ, Shi JQ, Feng LF (2018) A fuzzy comprehensive evaluation methodology for rock burst forecasting using microseismic monitoring. Tunn Undergr Space Technol 80(Oct.):232-245

Dalkey N, Helmer O (1963) An experimental application of the DELPHI method to the use of experts. Manage Sci 9(3):458-467

Feng XT, Webber S, Ozbay MU, Wang YJ (1996) An expert system on assessing rockburst risks for South African deep gold mines. J Coal Sci Eng 2(2):23-32

Guo J, Zhang WX, Zhao Y (2018) A multidimensional cloud model for rockburst prediction. Chin J Rock Mech Eng 37(5):1199-1206 (In Chinese)

Gao CL, Li SC, Wang J, Li LP, Lin P (2017) The risk assessment of tunnels based on grey correlation and entropy weight method. Geotech Geol Eng 36(3):1621-1631

Kubler S, Robert J, Derigent W, Voisin A, Traon Y (2016) A state-of the-art survey \& testbed of fuzzy AHP (FAHP) applications. Expert Syst Appl 65(Dec.):398-422

Li DY, Liu CY, Gan WY (2009) A new cognitive model: cloud model. Int J Intell Syst 24(3):357-375

Luo D, Ye LL, Sun DC (2020) Risk evaluation of agricultural drought disaster using a grey cloud clustering model in Henan province, China. Int J Disast Risk Re 49:101759 
Liu QS, Wu J, Zhang XP, Tang LX, Chen B, Li WW, Xu JL (2020) Microseismic monitoring to characterize structure-type rockbursts: A case study of a TBM-excavated tunnel. Rock Mech Rock Eng 53(7):2995-3013

Liang WZ, Zhao GY, Wu H, Dai B (2019) Risk assessment of rockburst via an extended MABAC method under fuzzy environment. Tunn Undergr Space Technol 83(Jan.):533-544

Li DY, Du Y (2014) Artificial intelligence with uncertainty. National Defense Industry Press, Beijing (In Chinese)

Li Z, Liu Y (2010) Single rule reasoning mapping for the two dimensional normal cloud model. Trans Intell Syst 5(5):464-470

Li ZQ, Xue YG, Qiu DH, Xu ZH, Zhang XL, Zhou BH, Wang XT (2017) AHP-Ideal Point model for large underground petroleum storage site selection: an engineering application. Sustainability 9(12):2343

Li ZC, Yan XF (2018) Ensemble learning model based on selected diverse principal component analysis models for process monitoring. J Chemometr 32(6):e3010

Li SC, Zhou ZQ, Li LP, Xu ZH, Zhang QQ, Shi SS (2013a) Risk assessment of water inrush in karst tunnels based on attribute synthetic evaluation system. Tunn Undergr Space Technol 38(Sep.):50-58

Li SC, Zhou ZQ, Li LP, Shi SS, Xu ZH (2013b) Risk evaluation theory and method of water inrush in karst tunnels and its applications. Chin J Rock Mech Eng 32(9):1858-1867 (In Chinese) Lai CG, Chen XH, Chen XY, Wang ZL, Wu XS, Zhao SW (2015) A fuzzy comprehensive evaluation model for flood risk based on the combination weight of game theory. Nat Hazards 77(2):1243-1259 
Moore B (1981) Principal component analysis in linear systems: Controllability, observability, and model reduction. IEEE T Automat Contr 26(1):17-32

Okoli C, Pawlowski SD (2004) The delphi method as a research tool: an example, design considerations and applications. Inform Manage 42(1):15-29

Qiu DH, Li SC, Zhang LW (2013) Study on rockburst intensity prediction based on efficacy coefficient method. Appl Mech Mater 353-356:1277-1280

Russenes BF (1974) Analyses of rockburst in tunnels in valley sides. Dissertation, Norwegian Institute of Technology, The Trondherim

Sun JL, Liu BG, Chu ZF, Chen L, Li X (2018) Tunnel collapse risk assessment based on multistate fuzzy Bayesian networks. Qual Reliab Eng Int 34(8):1646-1662

Saaty TL (1990) Multicriteria decision-making: the analytic hierarchy process. Dissertation, University of Pottsburgh, The United States

Saaty TL (2008) Decision making with the analytic hierarchy process. Int J Servi Sci 1(1):83-98

Saaty TL (2003) Decision-making with the AHP: why is the principal eigenvector necessary. Eur J Oper Res 145(1):85-91

Shafiullah G, Al-Ruwaih FM (2020) Spatial-multivariate statistical analyses to assess water quality for irrigation of the central part of Kuwait. Bull Eng Geol Environ 79(1):27-37

Tudes S, Yigiter ND (2010) Preparation of land use planning model using GIS based on AHP: case study Adana-Turkey. Bull Eng Geol Environ 69(2):235-245

Wang D, Singh VP, Zhu YS (2007) Hybrid fuzzy and optimal modeling for water quality evaluation. Water Resour Res 43(5):W05415

Wang XT, Li SC, Xu ZH, Hu J, Pan DD, Xue YG (2019a) Risk assessment of water inrush in karst 
tunnels excavation based on normal cloud model. Bull Eng Geol Environ 78(5):3783-3798

Wang XT, Li SC, Xu ZH, Li XZ, Lin P, Lin CL (2019b) An interval risk assessment method and management of water inflow and inrush in course of karst tunnel excavation. Tunn Undergr Space Technol 92:103033

Wang XT, Li SC, Xu ZH, Lin P, Hu J, Wang WY (2019c) Analysis of factors influencing floor water inrush in coal mines: a nonlinear fuzzy interval assessment method. Mine Water Environ 38(1):81-92

Wang XT, Li SC, Xu ZH, Xue YG, Hu J, Li ZQ, Zhang B (2019d) An interval fuzzy comprehensive assessment method for rock burst in underground caverns and its engineering application. Bull Eng Geol Environ 78(7):5161-5176

Wang D, Zeng DB, Vijay PS, Xu PC, Liu DF, Wang YK, Zeng XK, Wu JC, Wang LC (2016a) A multidimension cloud model-based approach for water quality assessment. Environ Res 149(Aug.):113-121

Wold S, Esbensen K, Geladi P (1987) Principal component analysis. Chemom Intell Lab Syst 2(1-3):37-52

Wang YC, Yin X, Jing HW, Liu RC, Su HJ (2016b) A novel cloud model for risk analysis of water inrush in karst tunnels. Environ Earth Sci 75(22):1450

Wang YC, Jing HW, Yu LY, Su HJ, Luo N (2017) Set pair analysis for risk assessment of water inrush in karst tunnels. Bull Eng Geol Environ 76(3):1199-1207

Wang JA, Park HD (2001) Comprehensive prediction of rockburst based on analysis of strain energy in rocks. Tunn Undergr Space Technol 16(1):49-57

Wang YH, Li WD, Lee PKK, Tsui Y, Tham LG (1998) Method of fuzzy comprehensive 
evaluations for rockburst prediction. Chin J Rock Mech Eng 17(5):493-501 (In Chinese)

Xue YG, Li ZQ, Qiu DH, Zhang LW, Zhao Y, Zhang XL, Zhou BH (2019) Classifcation model for surrounding rock based on the PCA-Ideal point method: an engineering application. Bull Eng Geol Environ 78(5):3627-3635

Xu ZH, Li SC, Li LP, Chen J, Shi SS (2011) Construction permit mechanism of karst tunnels based on dynamic assessment and management of risk. Chin J Geotech Eng 33(11):1714-1725 (In Chinese)

Yan HY, Wu D, Huang Y, Wang GY, Shang MS, Xu JJ, Shi XY, Shan K, Zhou BT, Zhao YF (2017) Water eutrophication assessment based on rough set and multidimensional cloud model. Chemometr Intell Lab 164:103-112

Zhang GH, Jiao YY, Chen LB, Wang H, Li SC (2016) Analytical model for assessing collapse risk during mountain tunnel construction. Can Geotech J 53(2):326-342

Zhang LW, Zhang XY, Wu J, Zhao DK, Fu H (2020) Rockburst prediction model based on comprehensive weight and extension methods and its engineering application. Bull Eng Geol Environ 79(9):4891-4903

Zhou ZQ, Li SC, Li LP, Shi SS, Xu ZH (2015) An optimal classification method for risk assessment of water inrush in karst tunnels based on grey system theory. Geomech Eng 8(5):631-647

Zhou KP, Lei T, Hu JH (2013) RS-TOPSIS model of rockburst prediction in deep metal mines and its application. Chin J Rock Mech Eng 32(Supp.2):3705-3711 (In Chinese)

Zhou KP, Lin Y, Hu JH, Zhou YL (2016) Grading prediction of rockburst intensity based on entropy and normal cloud model. Rock Soil Mech 37(Supp.1):596-602 (In Chinese) 


\section{Figures}

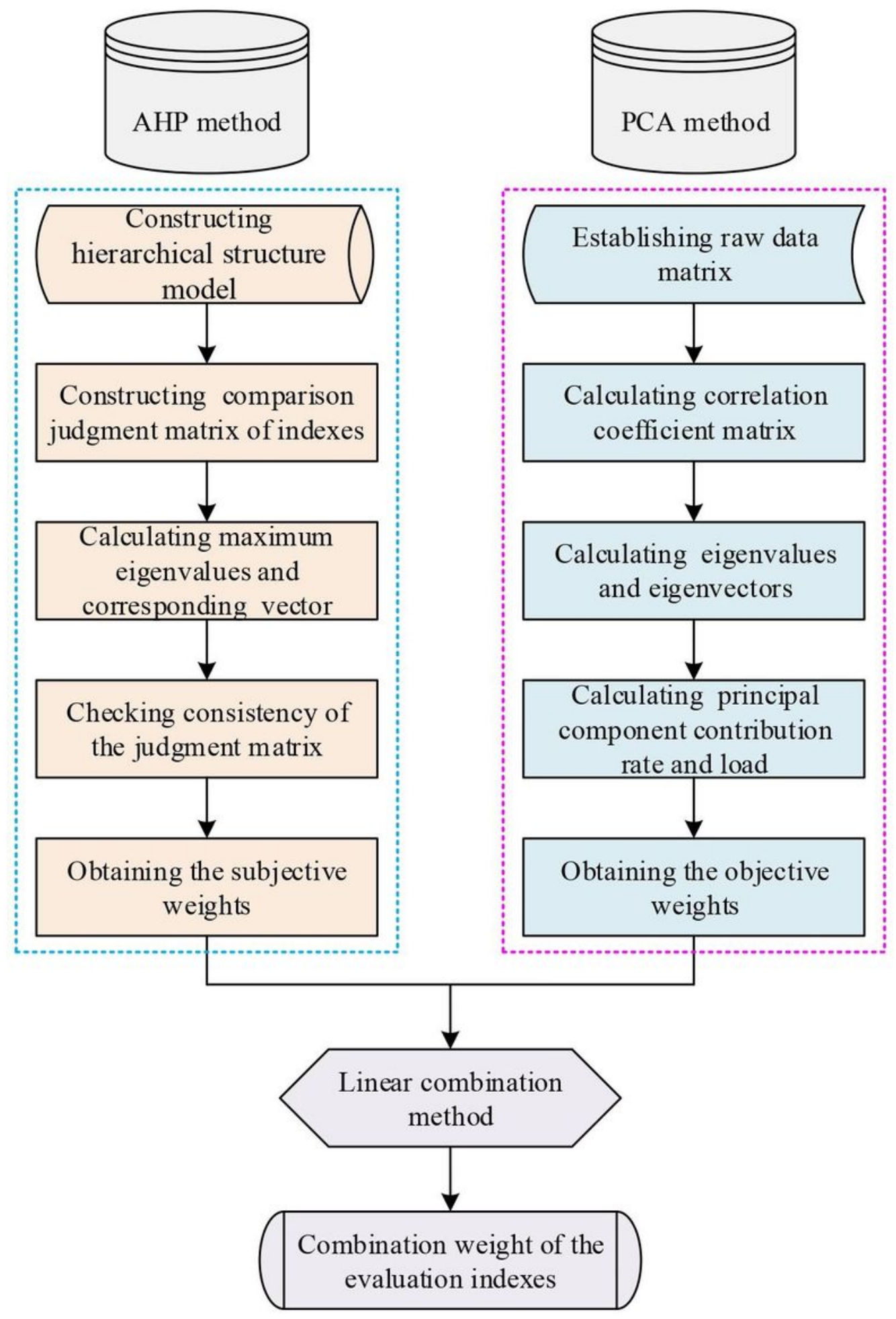

Figure 1

A general process for the establishment of combination weights. 


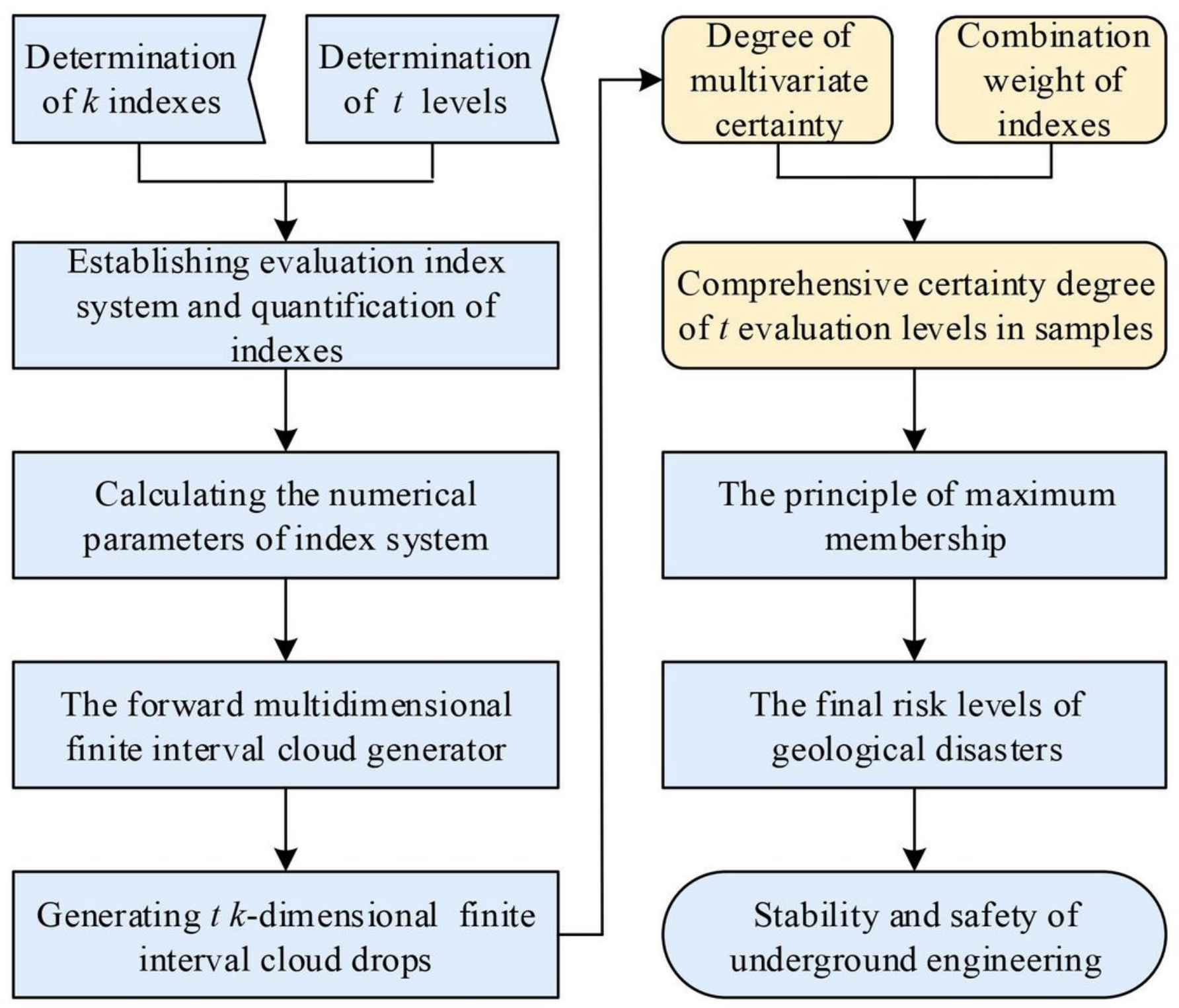

Figure 2

A framework of geological disaster risk assessment by the MFICM. 


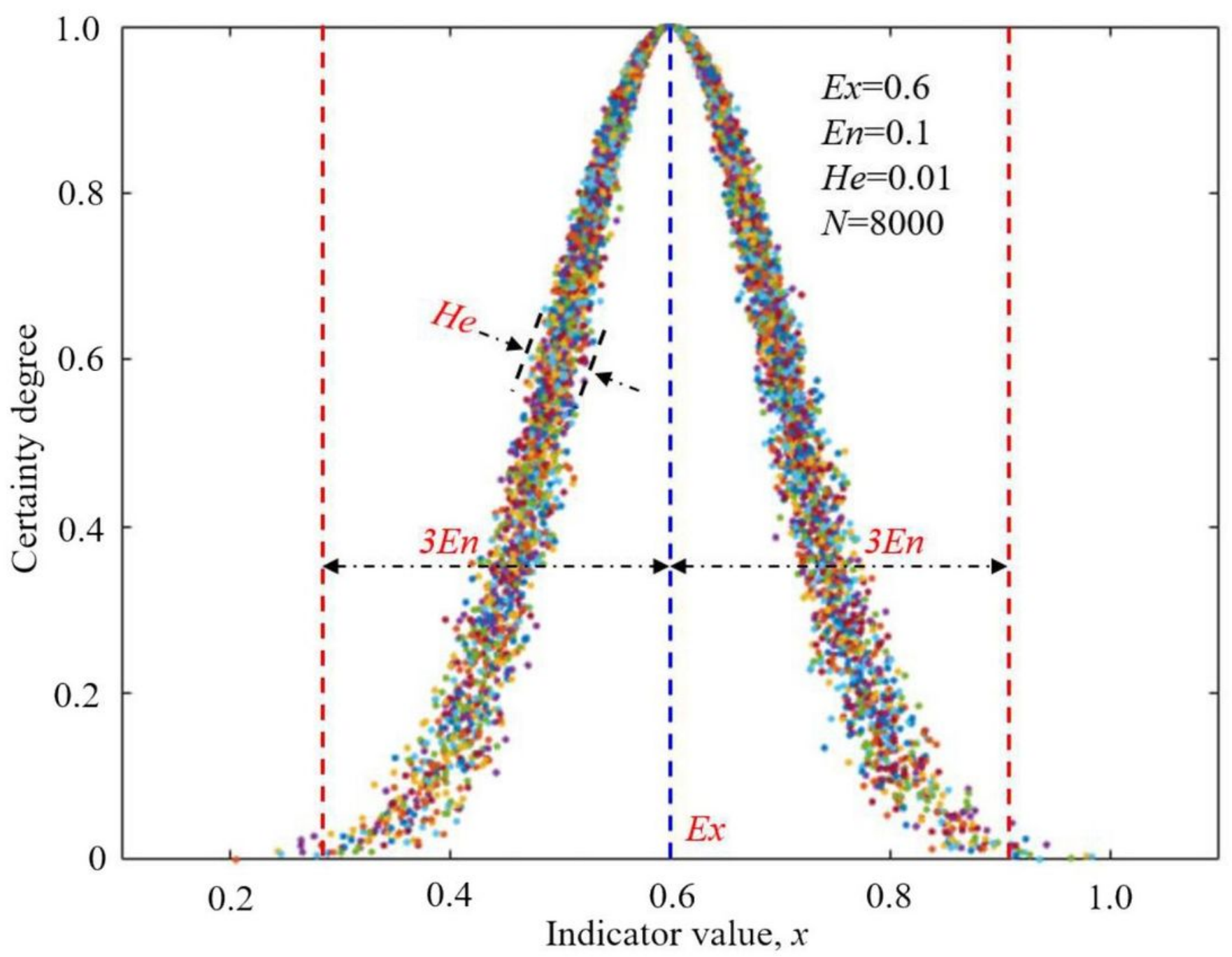

Figure 3

An illustration of the numerical characteristics of the normal cloud model.
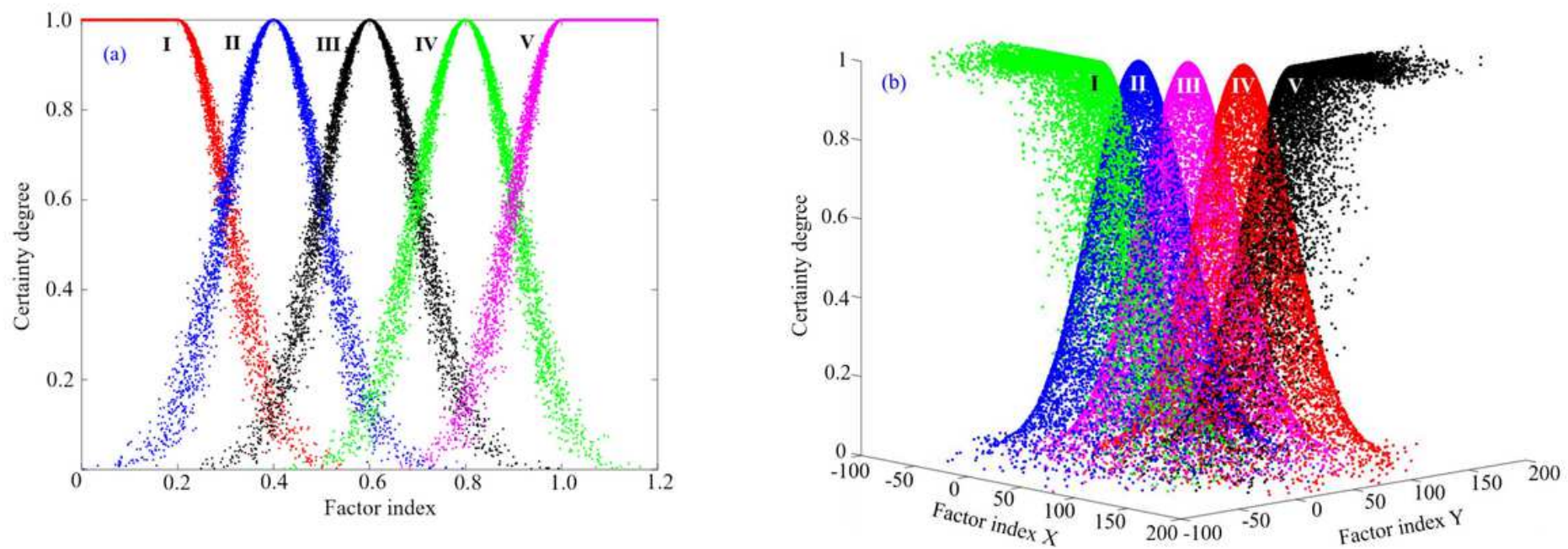


\section{Figure 4}

A schematic of the one-dimensional (a) and two-dimensional (b) finite interval cloud model.

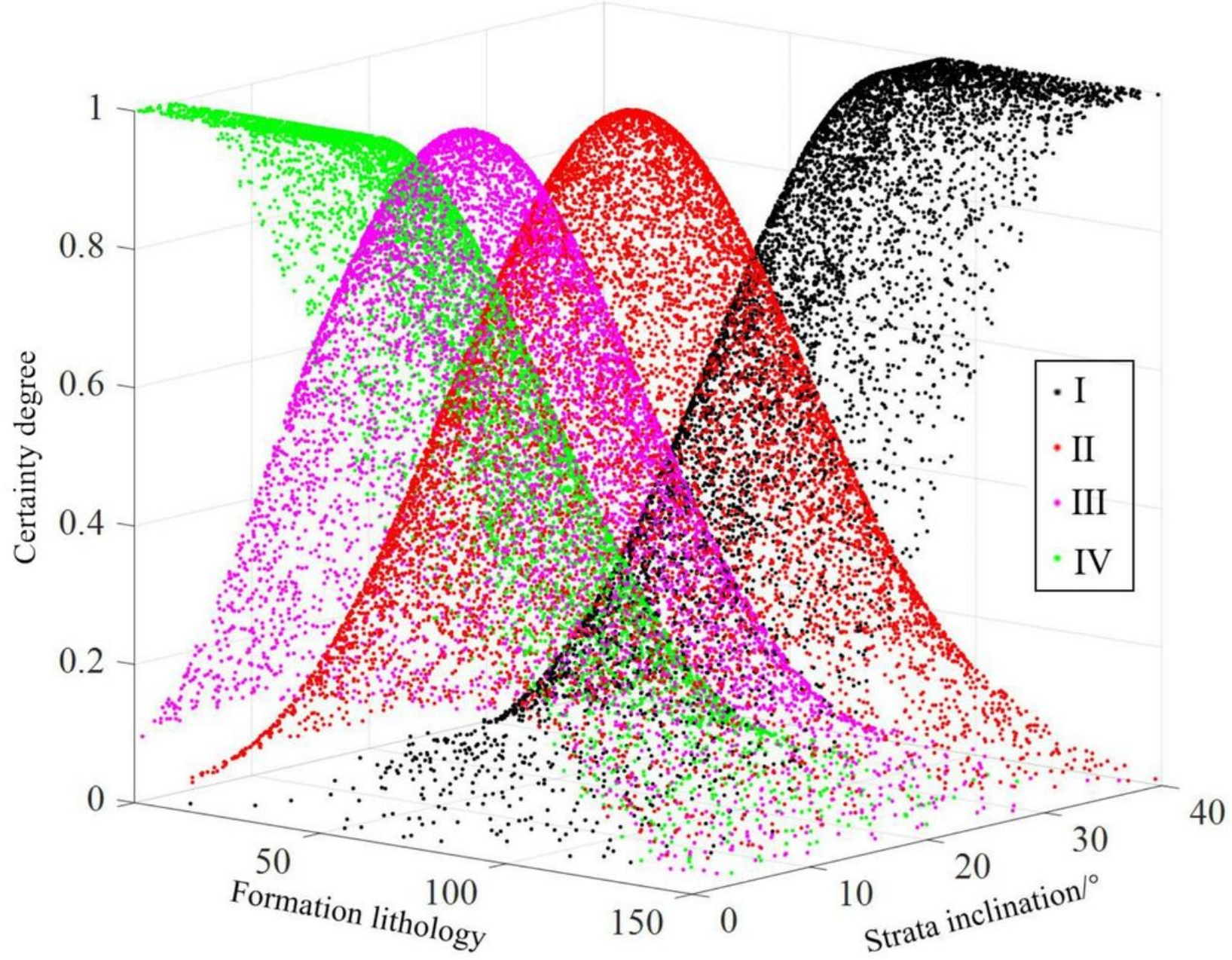

Figure 5

The two-dimensional finite interval cloud for indexes of the formation lithology and strata inclination.
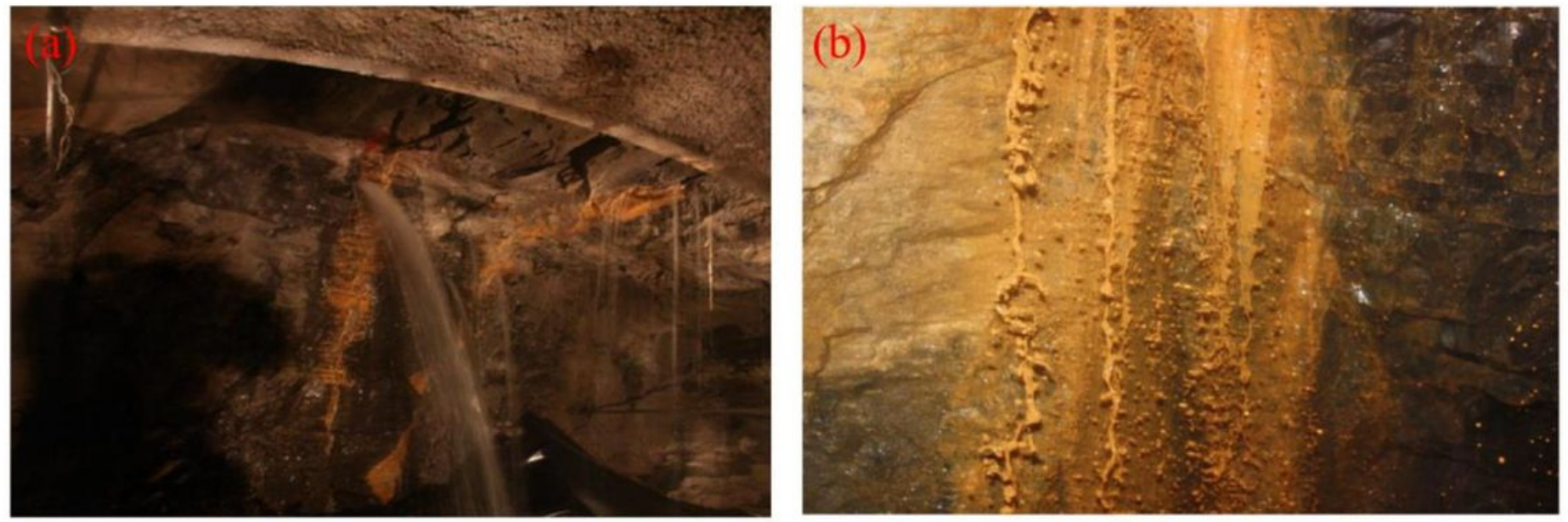
Figure 6

Water inrush at K19+512 (a) and K19+536 (b) [belonging to sample 3] in Jigongling Tunnel (Li et al. 2013a).

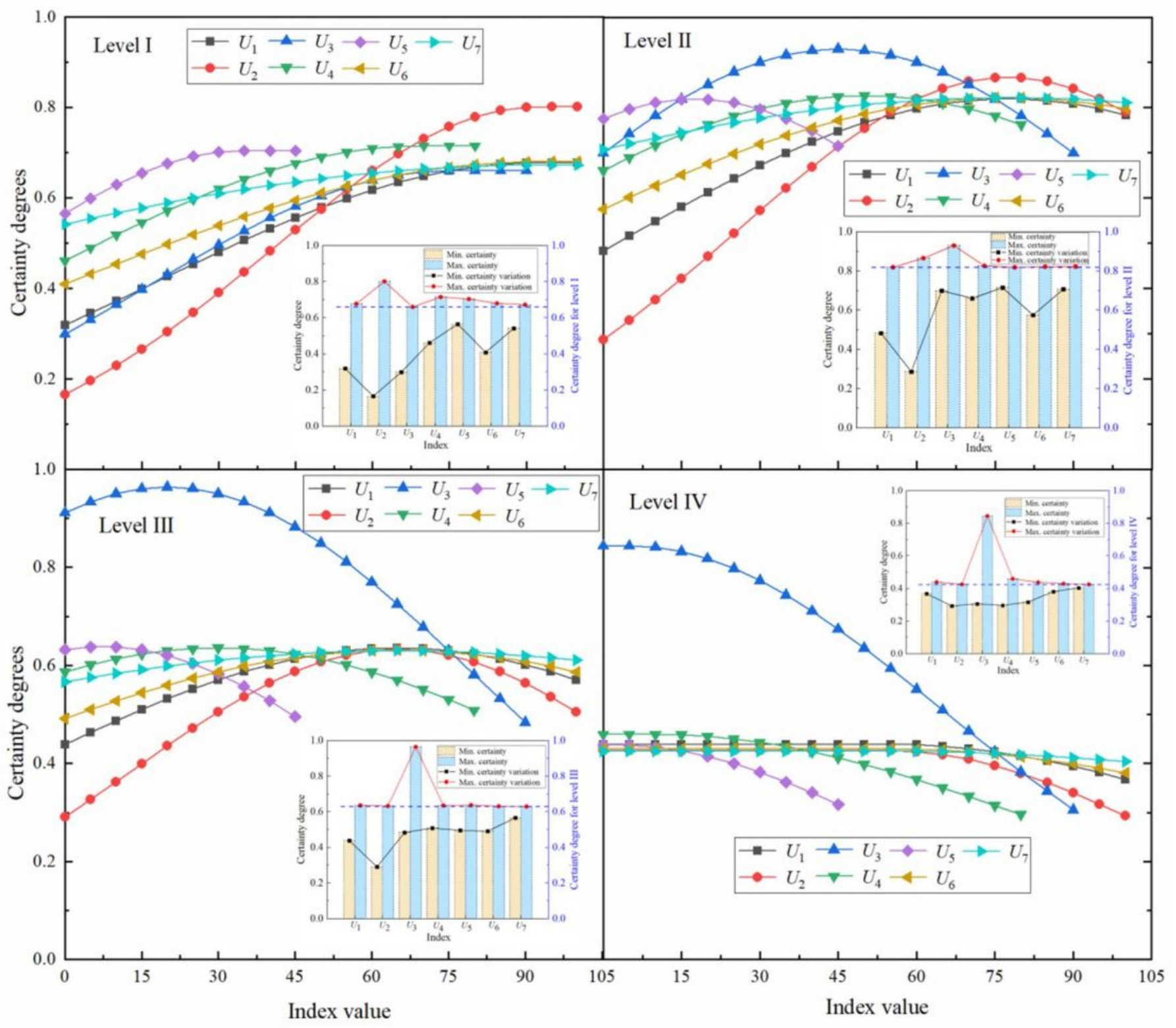

\section{Figure 7}

Effect of each index value variation on each water inrush risk level. 

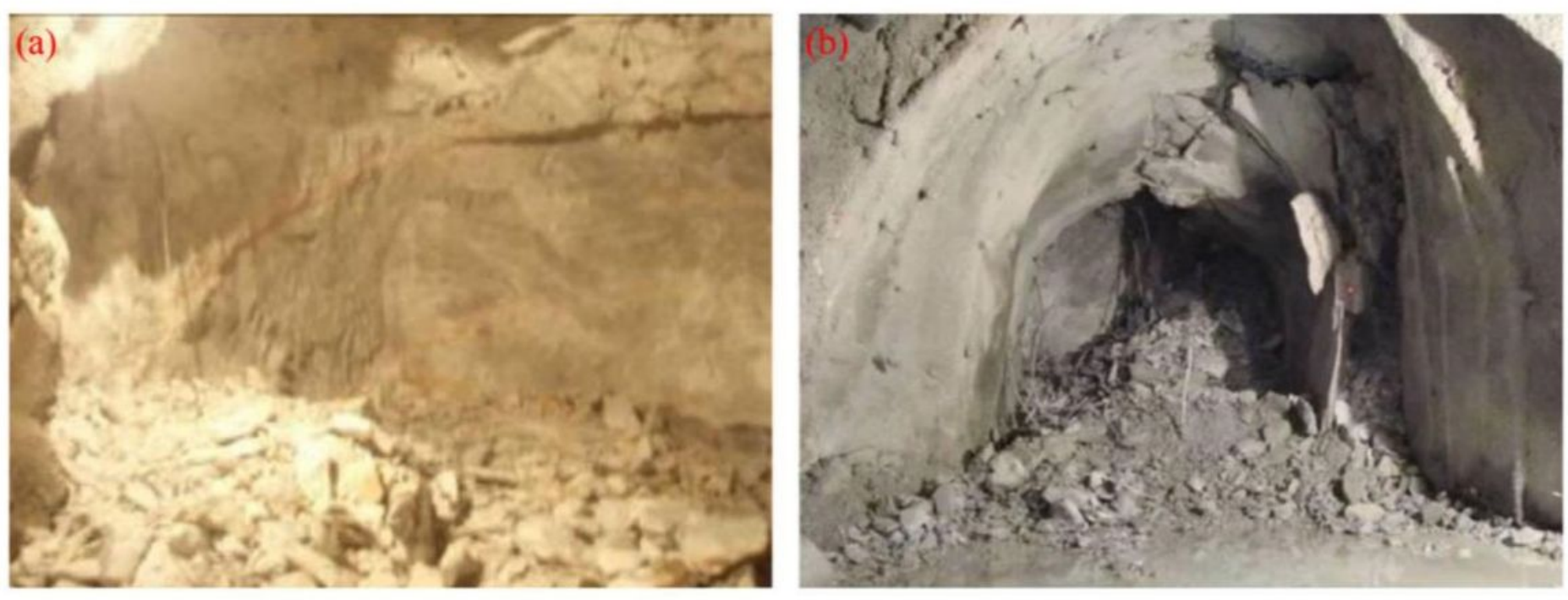

Figure 8

Rock burst conditions of the diversion tunnels at BK6+754 (a) and at AK9+485 490 (b) of Jinping II hydropower station (Zhang et al. 2020). 


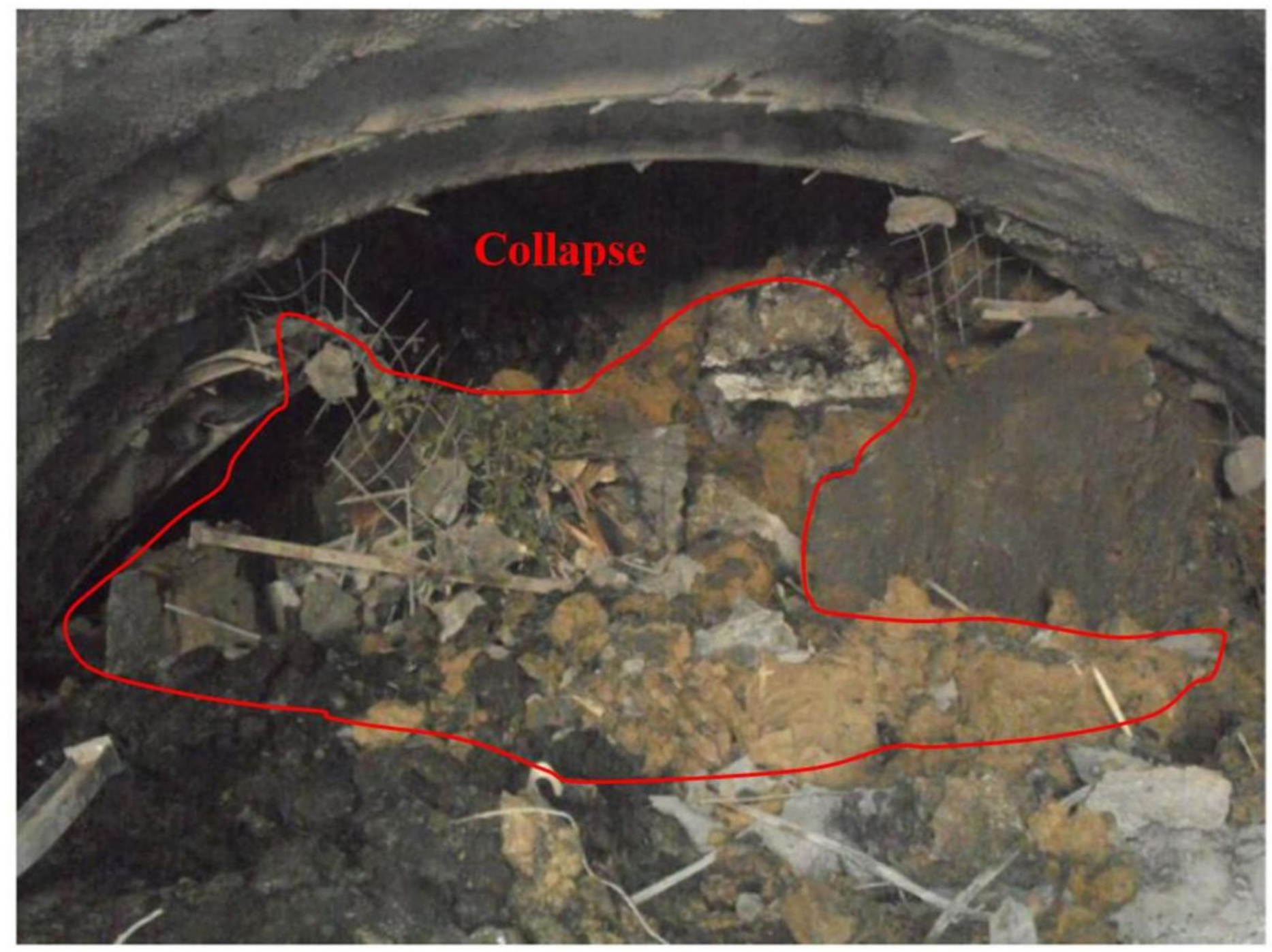

Figure 9

A collapse appeared at the mileage YK52+965 in Qiyueshan Tunnel (Gao et al. 2017). 